\title{
RAZGLEDI
}

\section{NARAVNE IN UMETNE PREGRADE TER Z NJIMI POVEZANI HIDRO-GEOMORFNI PROCESI}

\author{
AVTORJA \\ dr. Blaž Komac \\ Znanstvenoraziskovalni center Slovenske akademije znanosti in umetnosti, Geografski inštitut Antona Melika, \\ Gosposka ulica 13, SI - 1000 Ljubljana, Slovenija \\ blaz.komac@zrc-sazu.si
}

\section{dr. Matija Zorn}

Znanstvenoraziskovalni center Slovenske akademije znanosti in umetnosti, Geografski inštitut Antona Melika, Gosposka ulica 13, SI - 1000 Ljubljana, Slovenija

matija.zorn@zrc-sazu.si

DOI: $10.3986 / G V 88204$

UDK: 551.435.62:622.515

COBISS: 1.02

\section{IZVLEČEK}

\section{Naravne in umetne pregrade ter z njimi povezani hidro-geomorfni procesi}

$V$ članku predstavljamo hidro-geomorfne procese, ki so povezani z naravnimi in umetnimi pregradami. Ob zajezitvah, ki nastajajo za pregradami, prihaja zaradi različnih vzrokov, kot je nihanje vodne gladine, do proženja zemeljskih plazov in skalnih podorov. Takšni pojavi lahko povzročijo prelitje ali podrtje naravnih pa tudi umetnih pregrad. V tem oziru posebej poudarjamo Vajontski zdrs, ki je zaradi človeškega vzroka, velikosti in katastrofalnih posledic eden bolj znanih tovrstnih pojavov v Evropi. Predstavljamo tudi povečini spregledane pojave $v$ Sloveniji ter nekaj večjih pojavov po svetu.

\section{KLJUČNE BESEDE}

geografija, hidro-geomorfni procesi, skalni podor, zemeljski plaz, plazovne pregrade, poplave, porušitev jezov, prožnost

\section{ABSTRACT \\ Natural and man-made dams and related hydro-geomorphic processes}

The article presents hydro-geomorphic processes associated with natural and artificial dams. Landslides and rockfalls are triggered behind the dams due to different causes, e.g. fluctuation of the water level. Such phenomena can cause overspilling or demolish natural and artificial dams. In this regard, the article presents the Vaiont rockslide, which is due to human-related causes, its size and the catastrophic consequences one of the most well-known phenomena in Europe. Some other examples from the world and in Slovenia are presented.

KEY WORDS

geography, hydro-geomorphic processes, rockfall, landslide, landslide dams, floods, dam breach, resilience

Uredništvo je prispevek prejelo 23. septembra 2016. 


\section{Uvod}

V lanskem Geografskem vestniku (87-1) smo predstavili metodološki pristop k izdelavi zemljevidov verjetnosti za nastanek obpotresnih zemeljskih plazov in skalnih podorov v Sloveniji (Komac 2015). Možnost nastanka zemeljskih plazov smo ocenili z Newmarkovo metodo, skalnih podorov pa $\mathrm{z}$ empirično enačbo. Opisali smo tudi vpliv reliefa na lego obpotresnih pobočnih procesov z vidika njihove večje gostote v ovršjih gora in omenili nekatere posledice, kot so prispevanje sedimentov v vodotoke in možnost njihovega zajezevanja. Zajezitev vodotokov s strani skalnih podorov je v reviji tudi že bila obravnavana, na primer zgodovinski podori z Dobrača, ki so leta 1348 zajezili Ziljo (Zorn 2002a), ter skalni podor pri planini Polog, ki je leta 2004 zajezil Tolminko (Komac in Zorn 2009).

Pobočni procesi, ki so povezani z naravnimi zajezitvami, so v svetu pogosti posebej na potresno dejavnih območjih (Schuster 1986; Costa in Schuster 1988; Korup 2002; Korup, McSaveney in Davies 2004; Komac, Natek in Zorn 2008; Evans in ostali 2011b; Fan in ostali 2012). Ob potresu leta 2008 v kitajski provinci Wenchuan (magnituda 7,9) je prišlo do delne (40\%) ali popolne (60\%) zajezitve rek na 828 krajih. Pobočni procesi so povezani tudi z umetnimi zajezitvami. Zemeljski plazovi in skalni podori lahko nastanejo med gradnjo pregrad, ob polnjenju zajezitev ali kasneje.

V članku obravnavamo vpliv naravnih zajezitev na pobočne procese in obratno, vpliv pobočnih procesov na zajezitve oziroma $\mathrm{z}$ njimi povezane poplave. Obravnavamo tudi umetne zajezitve, ki so pogosto vzrok za nastanek hidro-geomorfnih procesov. V povezavi s slednjimi poudarjamo Vajontski zdrs (poglavje 3.1), njegove vzroke in $\mathrm{z}$ njim povezane posledice.

\section{Naravne pregrade}

Na potresno ogroženih območjih, zlasti pa v ozkih rečnih dolinah v gorskem svetu, so zemeljski plazovi in skalni podori pogosto tako veliki, da prekrijejo dolinsko dno (na primer podori z Dobrača; Zorn 2002a; slika 1), ga zatrpajo in ustvarijo tudi do več sto metrov visoke potresno-plazovne ali potresno-podorne naravne pregrade. Za njimi po navadi že v nekaj dneh nastanejo jezera. Povod za sprožitev so lahko tudi obilne padavine. Pregrade pomenijo dvojno nevarnost: nastajajoče jezero lahko zalije naselja nad njim, ogroženi pa so tudi prebivalci pod njim, saj se pregrada lahko poruši.

Takšne pregrade so na družbo vplivale že v prazgodovini. Na severozahodu Združenih držav Amerike so na primer preprečile migracije tihomorskega lososa v notranjost. Sledilo je pomanjkanje hrane, ki je povzročilo propad staroselskih prebivalcev. Obratno pa je v perujskih Andih jezero za takšno pregrado zagotavljalo pitno vodo za mesto Chavín de Huantar v prvem tisočletju pred Kristusom (Evans in ostali 2011a, 2-3).

V nekaterih državah so sistematično zbirali podatke o naravnih pregradah - na Novi Zelandiji so jih evidentirali 232, v Švici 31, na Kitajskem pa kar 1239. Da lahko močan potres povzroči nekaj sto takšnih pregrad smo na primeru potresa leta 2008 v Wenchuanu omenili v uvodu. V Italiji ugotavljajo, da se naravne pregrade pogosteje pojavljajo od 18. stoletja, kar deloma povezujejo $\mathrm{z}$ malo ledeno dobo, predvsem pa z izsekavanjem gozda in dostopnostjo informacij (Tacconi Stefanelli, Catani in Casagli 2015). V Švici so nekatera izmed večjih jezer posledica pobočnih procesov. Primer je Davoško jezero (Bonnard 2011).

Costa in Schuster (1991) sta opisala 463 primerov zajezitev zaradi pobočnih procesov. Ugotovila sta, da se več kot polovica (55\%) pregrad podre že po enem tednu, večina (89\%) pa v času enega leta. Tacconi Stefanelli, Catani in Casagli (2015) pišejo, da se v prvem mesecu po nastanku poruši $65 \%$ pregrad, medtem ko jih je $20 \%$ stabilnih tudi prek enega leta, $10 \%$ tudi do prek deset let. Podobno Fan in ostali (2012) omenjajo, da v $60 \%$ primerov pride do "preboja « pregrad v enem mesecu po nastanku jezu ter, da kasnejše preboje pospešijo intenzivne padavine. Omenjajo tudi, da prej ali slej pride do preboja v večini, $86 \%$ primerov. Največ pregrad se podre zaradi prelitja. Voda v plazovini ustvari strugo 
ter jo nato zaradi velikega strmca razmeroma hitro erozijsko poglobi in razširi. Večji prerez omogoči še večji pretok, dokler pozitivna povratna zveza ne privede do podrtja jezu in hipnega razlitja preostale vode. Poplavni val je po navadi zelo velik in uničujoč. S seboj prenaša veliko sedimentov, ki dolvodno ustvarjajo prostrane terase. Nekateri jezovi se podrejo zaradi pronicanja vode skozi porozne sedimente plazov, drugi pa zaradi nastanka sekundarnih plazov na pregradi ali na pobočjih nad jezerom. Do podrtja ne pride, če gradivo sestavljajo veliki kamninski bloki in je gradivo dovolj porozno, da je mogoče pronicanje vode ali če je površina jezera tako velika, da izhlapevanje uravna pritok vode. Prelitje lahko prepreči človek z odstranjevanjem gradiva ali kopanjem kanalov.

Ob podrtju jezu na reki Bairaman v Papui Novi Gvineji je nastal $80 \mathrm{~m}$ debel drobirski tok, ki je še $39 \mathrm{~km}$ pod jezom meril $8 \mathrm{~m}$. Pregrada podora »La Josefina « na reki Paute v Ekvadorju se je porušila po 26 letih, reka je poplavljala v dolžini $100 \mathrm{~km}$. Ob preboju pregrade pri gori Cayley v Kanadi je nastal drobirski tok, ki je potoval s hitrostjo $35 \mathrm{~m} / \mathrm{s}$. V severni Italiji je podor leta 1404 zajezil dolino Passer. Nastalo je $50 \mathrm{~m}$ globoko in $1 \mathrm{~km}$ dolgo jezero (Wildsee), ki je obstajalo skoraj 400 let. $V$ tem času je večkrat prišlo do porušitve delov pregrade. Leta 1409 je zaradi poplave kot posledice delnega podrtja v $25 \mathrm{~km}$ dolvodno ležečem Meranu umrlo 400 ljudi. Leta 1786 je zaradi zrušenja pregrade, ki je po potresu z magnitudo 7,7 nastala na reki Dadu v Sečuanu na Kitajskem, umrlo 100.000 ljudi. Potres februarja 1783 v Kalabriji je sprožil veliko zemeljskih plazov in nastalo je kar 215 jezer. Februarja 1911 je potres z magnitudo 7,6 v Pamirju v Tadžikistanu sprožil kamniti zdrs velikosti $2 \mathrm{~km}^{3}$. Nastal je $600 \mathrm{~m}$ visok jez, ki je največji znani naravni ali umetni jez na svetu. Reka pronica skozenj, a gladina jezera kljub temu narašča za 18,5 cm na leto (slika 2; Rybář, Stemberk in Wagner 2002, 67; Schuster in Alford 2004; Bonnard 2011, 105). V dolini Mayunmarca v Peruju se je aprila 1974 sprožil zemeljski plaz velikosti $1,2 \mathrm{~km}^{3}$ in ustvaril zajezitveno jezero. Naraščanje vode je sprožilo še več plazov, ki so uničili avtocesto ob obali.

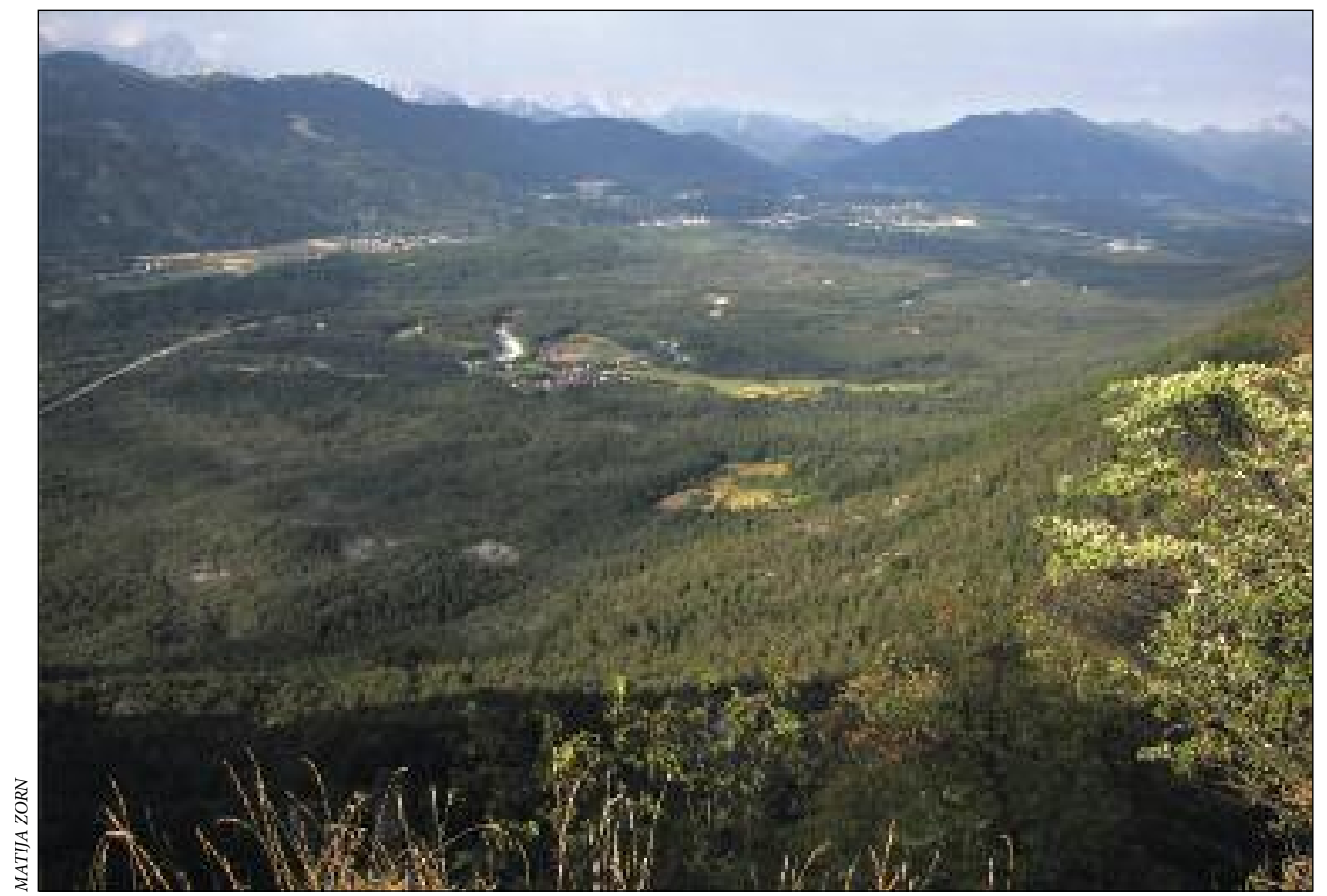

Slika 1: Gozdnato območje Schütt na severnem podnožju Dobrača v Spodnji Ziljski dolini je povsem prekrito s podornim gradivom (Zorn 2002a). Vozadju je naselje Podklošter. 


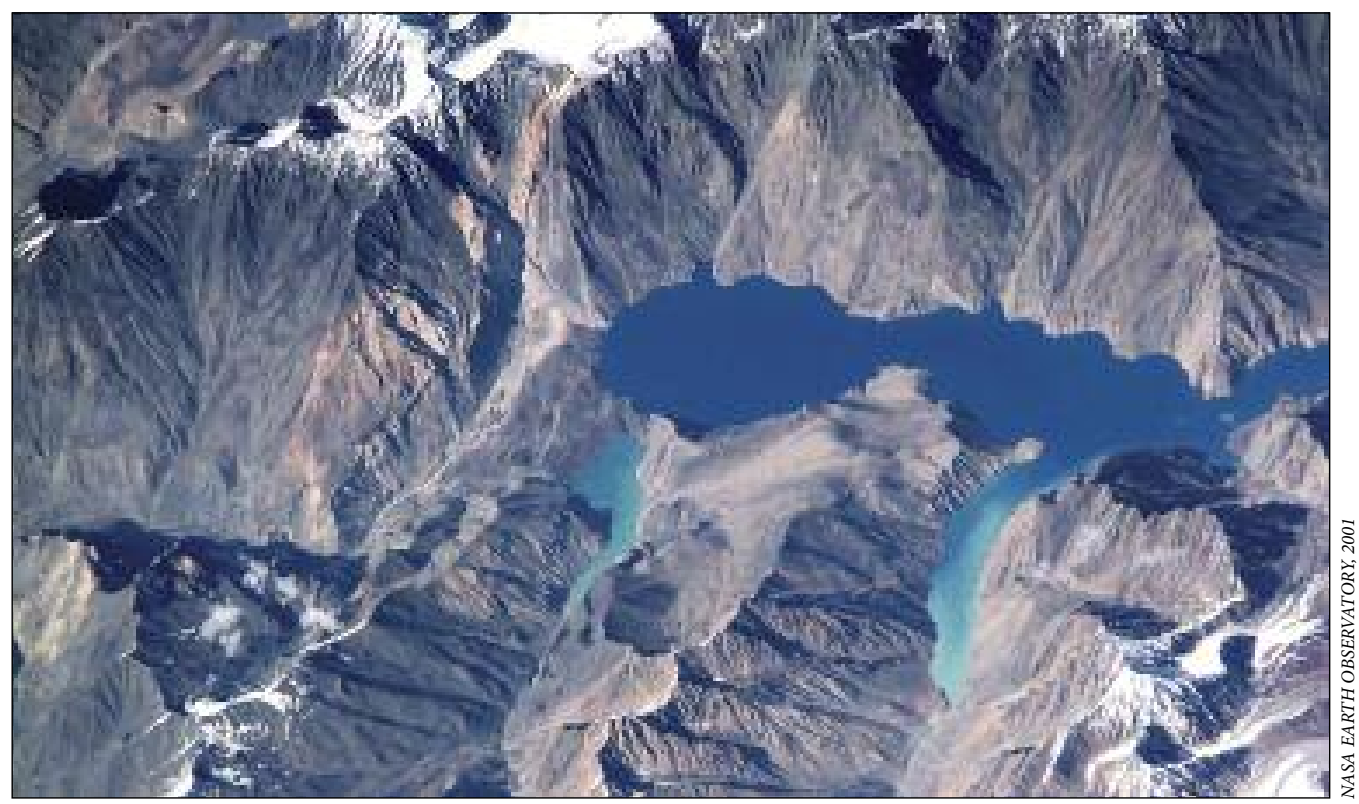

Slika 2: Jezero Sarez v Tadžikistanu, ki je nastalo zaradi obsežnega kamnitega zdrsa ob potresu leta 1911, je dolgo $61 \mathrm{~km}$, globoko $500 \mathrm{~m}$ in vsebuje $17 \mathrm{~km}^{3}$ vode. Oblasti se bojijo zdrsov v jezero in posledičnih poplavnih valov, ki bi preskočili jez in povzročili razdejanje dolvodno (medmrežje 1).

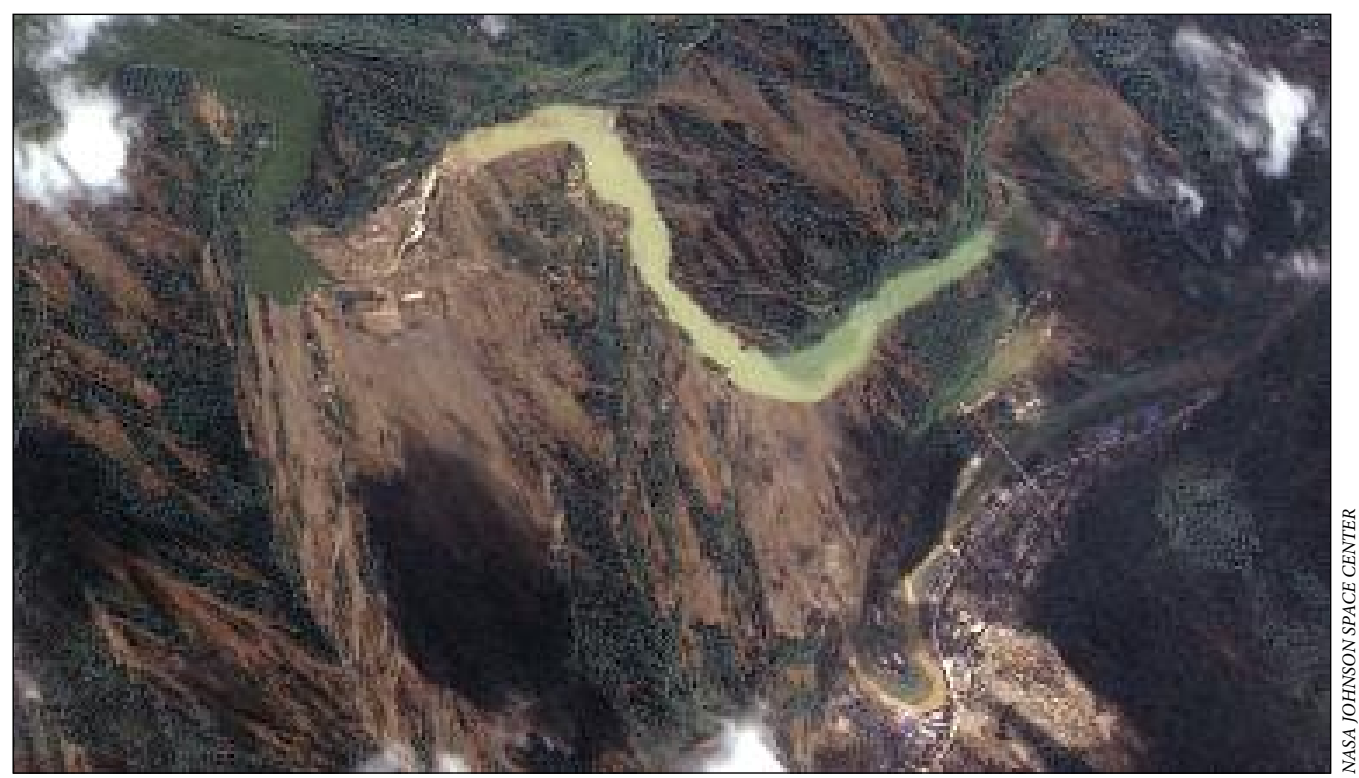

Slika 3: Reka Jianjiang je za 124 m visokim plazom, ki se je sprožil ob potresu v Sečuanu na Kitajskem maja 2008, $v 26$ dneh ustvarila jezero $s 229,5$ milijona $\mathrm{m}^{3}$ vode. Vodo so začeli odvajati po umetnem kanalu, ki se je zaradi erozije močno razširil. O veliki erozivnosti reke priča kalna voda, ki je vidna na posnetku (medmrežje 2). 


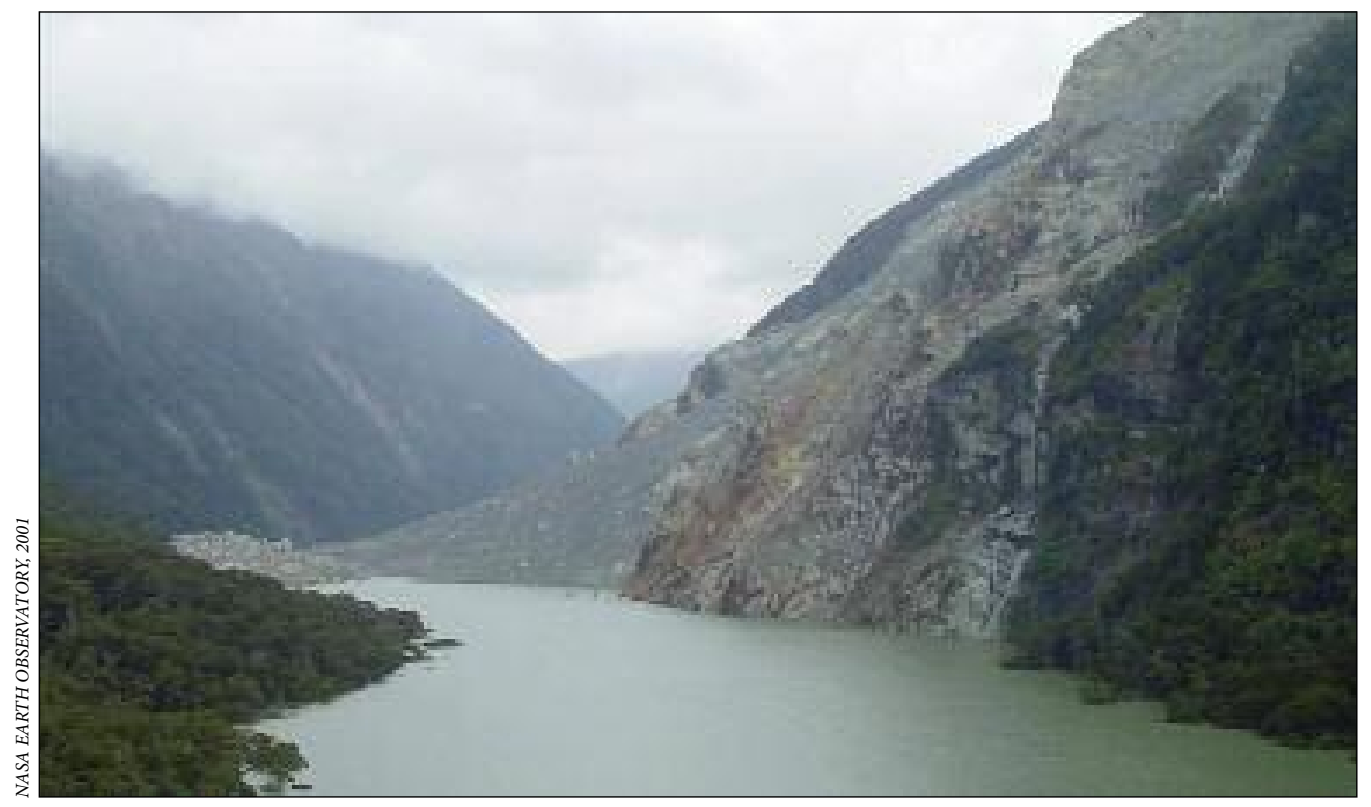

Slika 4: Pregrada, ki jo je 29. 8. 2007 na reki Young na Novi Zelandiji ustvaril skalni podor, je visoka $100 \mathrm{~m}$ (Young ... 2008).

Decembra 1960 so ob enem najmočnejših zgodovinskih potresov doslej z magnituda 9,5 na obali južnega Čila nastali številni zemeljski plazovi in na stotine usadov. Večji zemeljski plaz s 40 milijonov $\mathrm{m}^{3}$ gradiva je zajezil reko Río San Pedro v bližini jezera Riňihue (Rybář, Stemberk in Wagner 2002).

Številnim takšnim pojavom smo bili priča tudi ob potresu v provinci Sečuan na Kitajskem leta 2008 (slika 3). Plazovi so v oddaljenosti $150 \mathrm{~km}$ od epicentra povsem razgalili pobočja in zajezili najmanj 34 rek ter ustvarili tako imenovana potresna jezera. Zaradi nevarnosti so nemudoma izselili več naselij. Na zemeljskem plazu, ki je ustvaril jezero Tangjiashan na reki Jianjiang, so skopali kanal, po katerem je voda začela odtekati iz jezera, s čimer so zmanjšali možnost porušitve pregrade. Pod jezom živi 1,3 milijona ljudi (medmrežje 2). Podobnih primerov po svetu je še veliko, zlasti v potresno aktivnih pokrajinah, kot je na primer Nova Zelandija (slika 4).

\subsection{Zajezitve v Sloveniji}

Tudi v Sloveniji smo bili predvsem v alpskih pokrajinah že priča podobnim pojavom. Številni so bili ob koncu pleistocena (Komac in Zorn 2007). V Zgornjem Posočju je takrat za podorom Kuntri, ki se je sprožil s pobočja Polovnika, nastalo mladokvartarno, tako imenovano Srpeniško jezero, ki je segalo v Bovško kotlino. Obstoj jezera dokazujejo več kot $200 \mathrm{~m}$ debele plasti jezerske krede (Kuščer in ostali 1974; Marjanac in ostali 2001; Zorn 2002b). Da skalni podori lahko tudi danes zajezijo vodotok, smo v Geografskem vestniku že pisali - zajezitev Tolminke leta 2004 (slika 5; Komac in Zorn 2009). Tudi velik zdrs s Trnovskega gozda pri Selu v Vipavski dolini (Popit 2010) je verjetno zajezil, gotovo pa preusmeril tok Vipave.

V približno istem obdobju kot podor Kuntri naj bi zahodno od Kobarida nastal tudi veliko manjši skalni podor Molida (slika 6). Zanj sicer ni dokazov, da bi povzročil kakšno zajezitev, so pa tako domnevali v drugi polovici 19. stoletja. Zgodovinar goriške grofije Carl von Czoernig ga je namreč datiral v čas okrog leta 585, saj je v njem videl razlog, da reka Soča danes teče od Kobarida proti Tolminu in 
ne, kot naj bi bilo še v rimskih časih, proti Robiču (Czoernig 1876). Da naj bi Soča v rimskih časih tekla od Kobarida proti zahodu, je Czoernig sklepal na podlagi rimskega pisca Plinija starejšega iz 1. stoletja, ki je naštel vse reke, ki se izlivajo v severni Jadran, a med Nadižo in izviri Timava ne omenja nobenega večjega vodotoka. Sprememba v rečnem toku Soče naj bi bila po Czoernigu (1876) posledica velike naravne ujme, ki je okrog leta 585 pustošila po severni Italiji in sosedstvu. O njej v delu Zgodovina Langobardov (Historia Langobardorum) poroča tudi langobardski zgodovinar Pavel Diakon iz 8. stoletja (Diakon 1988). Podor naj bi zajezil odtok iz smeri Kobarida proti zahodu in vode naj bi našle novo pot v smeri jugovzhoda oziroma proti Tolminu.

V Posočju je izpričanih več tovrstnih dogodkov ob idrijskem potresu 26. marca 1511. Dolvodno od mesta Idrija je skalni podor s Kobalovega hriba zajezil Idrijco. Jezero je zalilo mesto (slika 7) in pod njim ležeč rudnik živega srebra (Bizjak 2011 65; Cecić 2011, 27).

Skalni podori so najbolj pogosti v gorskem svetu. Znano je, da Jesenice ležijo na podornem gradivu izpod Planskega vrha. Približno deset milijonov $\mathrm{m}^{3}$ gradiva je za nekaj časa zajezilo Savo. Obstoj jezera, ki je segalo do Hrušice, dokazujejo sedimenti jezerske krede (Grimšičar 1988). Podoben učinek sta morda imela podora v Radovni (Zorn 2002b) in dolini Tolminke, katerega gradivo je doseglo območje Tolmina (Šifrer 1965).

Poznan je tudi zgodovinski zapis iz leta 1811, ko se je po hudem deževju s Plesišča pri Fali utrgal zemeljski plaz in zasul narasli potok Radoljno. Nastal je naravni jez, ki ga je voda po kratkem času predrla, tako da je »... pol ure naprej oddaljeno lovrenško fužino tako rekoč posnela in ni bilo več videti, kje je stala. Veliko kladivo, ki tehta nekaj stotov, so valovi odnesli. Po daljšem času so ga našli v Dravi pol ure

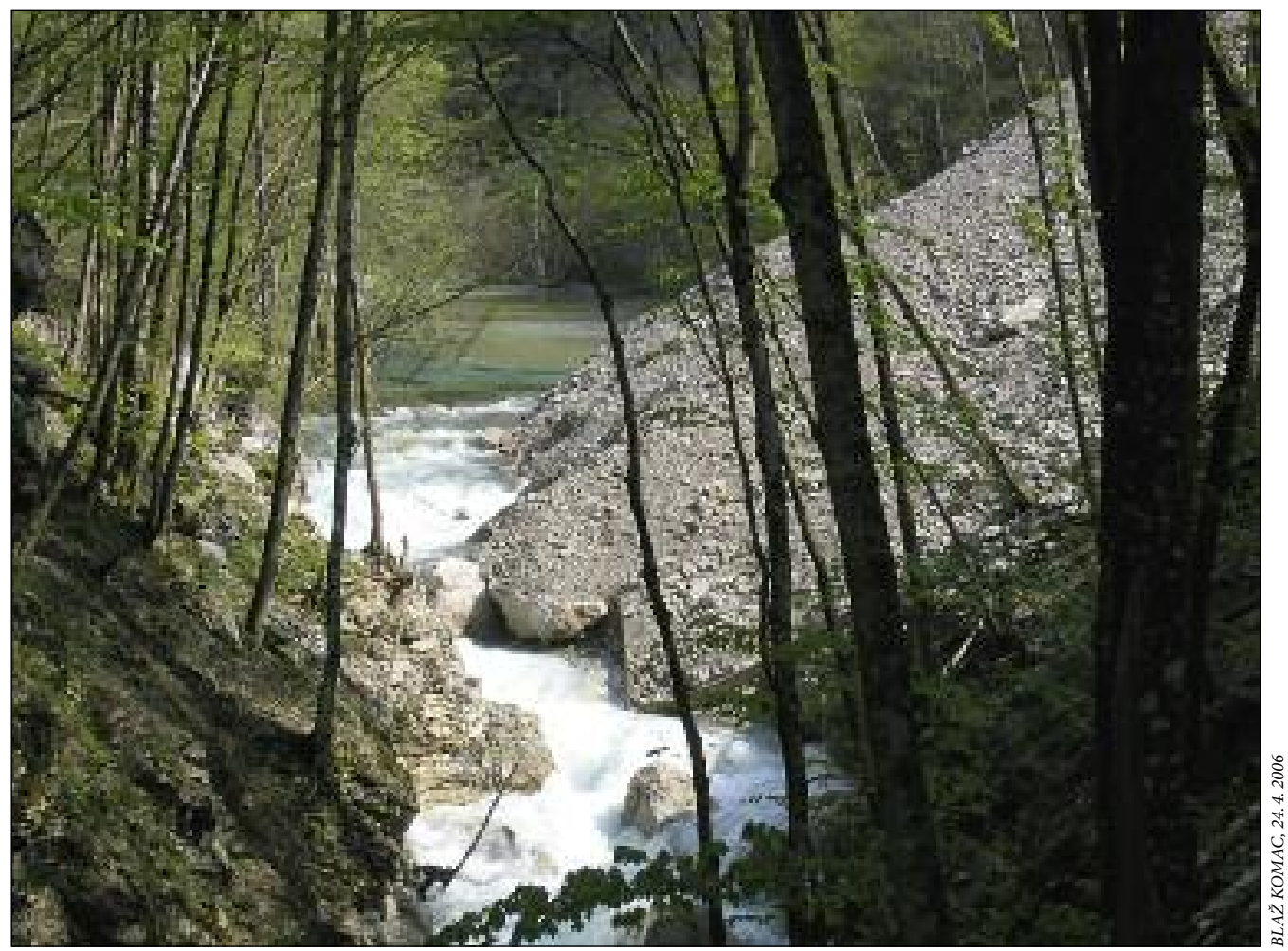

Slika 5: Skalni podor je leta 2004 pri planini Polog zajezil Tolminko; spredaj: preboj Tolminke skozi podorno gradivo, zadaj: jezero. 
pod Mariborom, voda ga je valila skoraj 4 milje daleč ... « (Trontelj 1997, 109). Ob poplavah 4. in 5. julija 1954 je zemeljski plaz zajezil Hudinjo na Dobrnici. Ko ga je voda prebila, »... se je začela razlivati s silovito močjo in po glavni cesti Vojnika drla od 1,5 do $2 \mathrm{~m}$ na visoko. Vojnik je bil zalit $v 20$ minutah. Vodni val je odnesel gasilski dom s temelji vred, šest gospodarskih poslopij, povsem pa je uničil številne kmetije. Železni most prek Hudinje je voda zaradi pritiska naplavljenih hlodov in drugega materiala premaknila za $400 \mathrm{~m}$... Svet med Višnjo vasjo in Vojnikom je bil nasut $80 \mathrm{~cm}$ na debelo sprodnimi in peščenimi naplavinami, ali pa je ostal popolnoma brez prsti... Od Vojnika proti Celju so vode prihrumele kot nad $1 \mathrm{~m}$ visok in $200 \mathrm{~m}$ širok vodni val. Po izlivu Hudinje v Voglajno je nastalo jezero, ki je zajemalo svet med Štorami na vzhodu, Arjo vasjo na zahodu in Škofjo vasjo na severu. VCelju so bile ulice pod 150 do $200 \mathrm{~cm}$ globoko vodo ... v mestu je voda porušila sedem mostov ... «(Jesenovec 1995, 32-33).

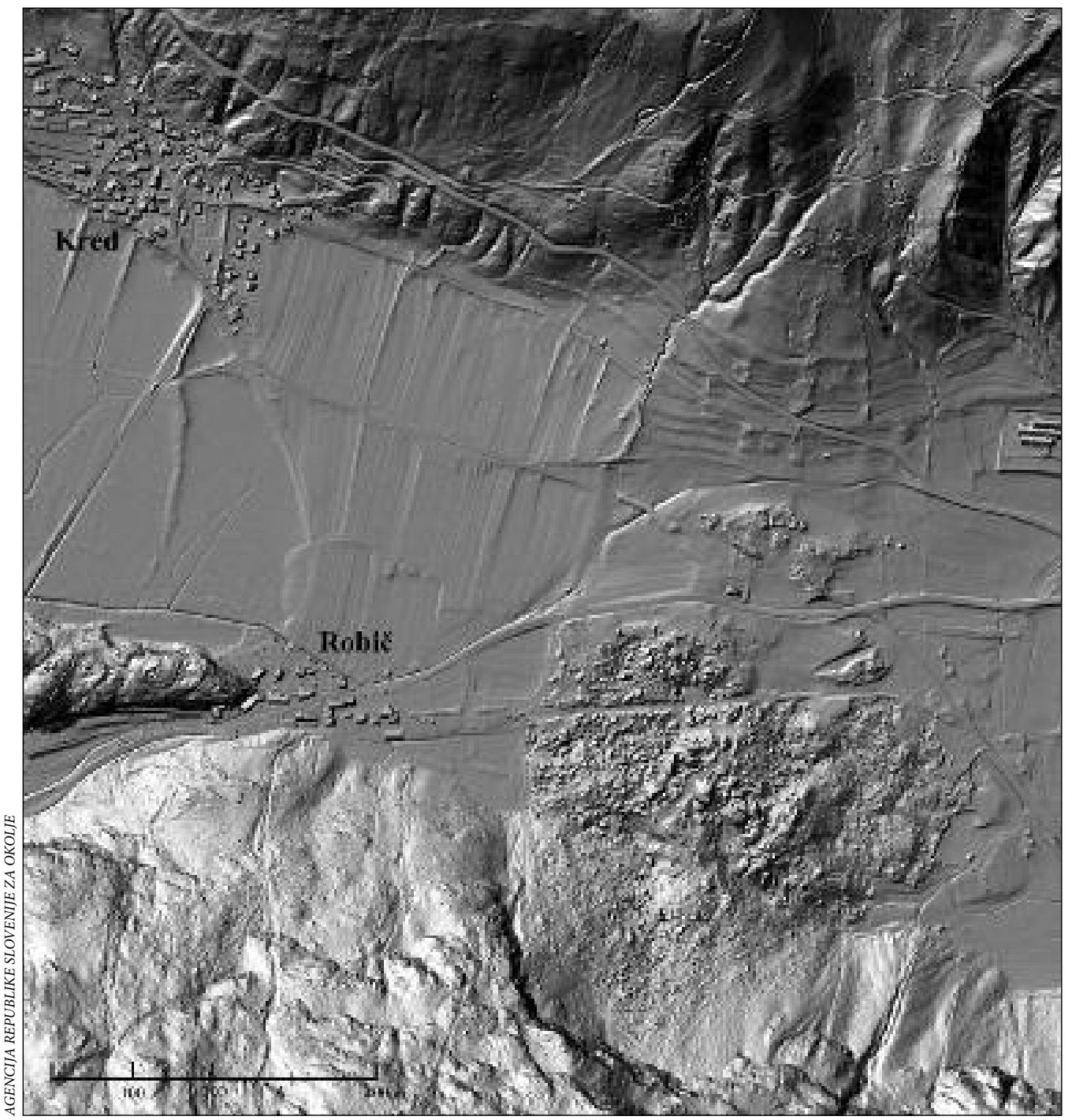

Slika 6: Skalni podor Molida. 
Blaž Komac, Matija Zorn Naravne in umetne pregrade ter $\mathrm{z}$ njimi povezani hidro-geomorfni procesi

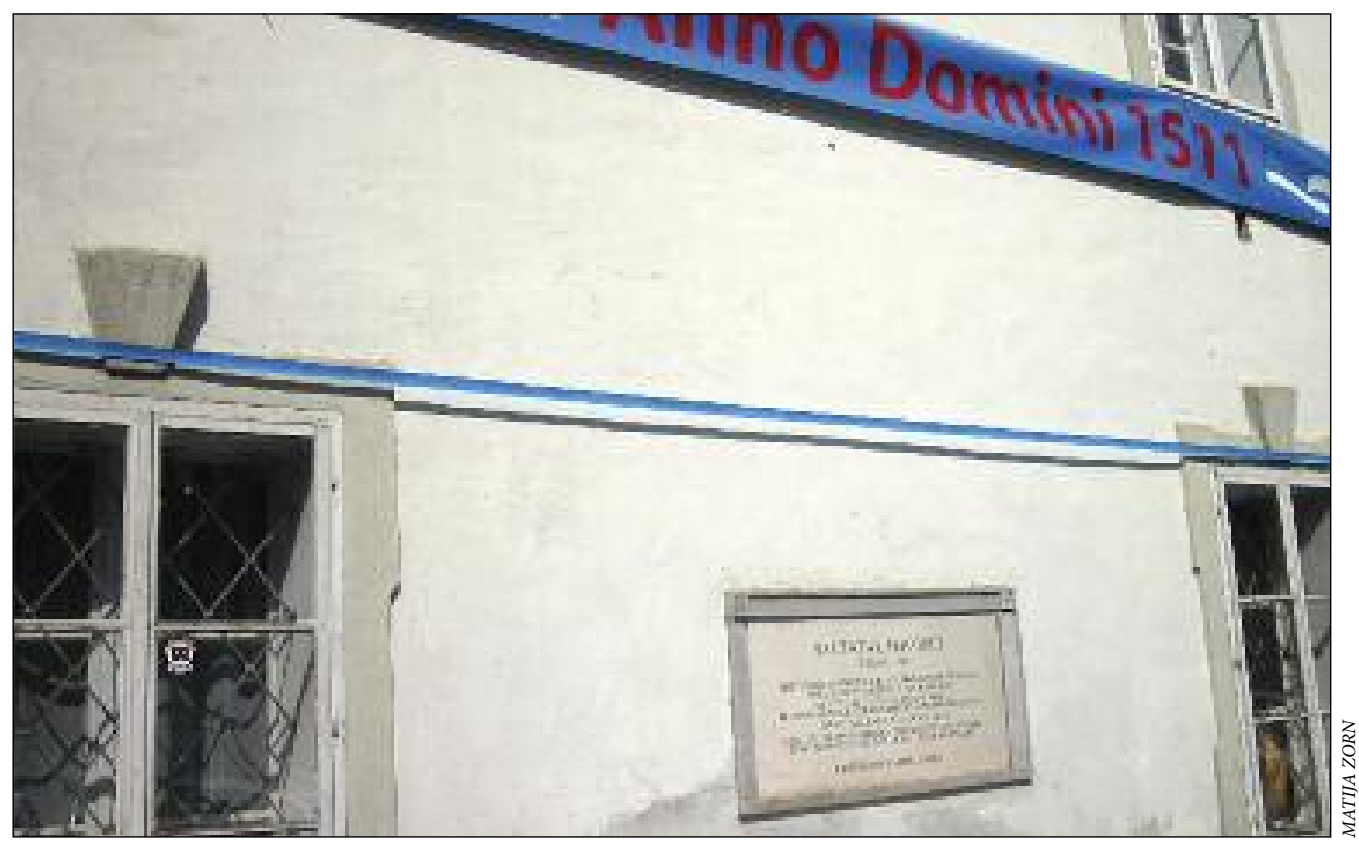

Slika 7: V starem mestnem jedru Idrije so ob 500. letnici poplave z modrimi trakovi označili njeno višino. Poplava je nastala zaradi podora, ki se je sprožil ob idrijskem potresu leta 1511 in zajezil Idrijco.

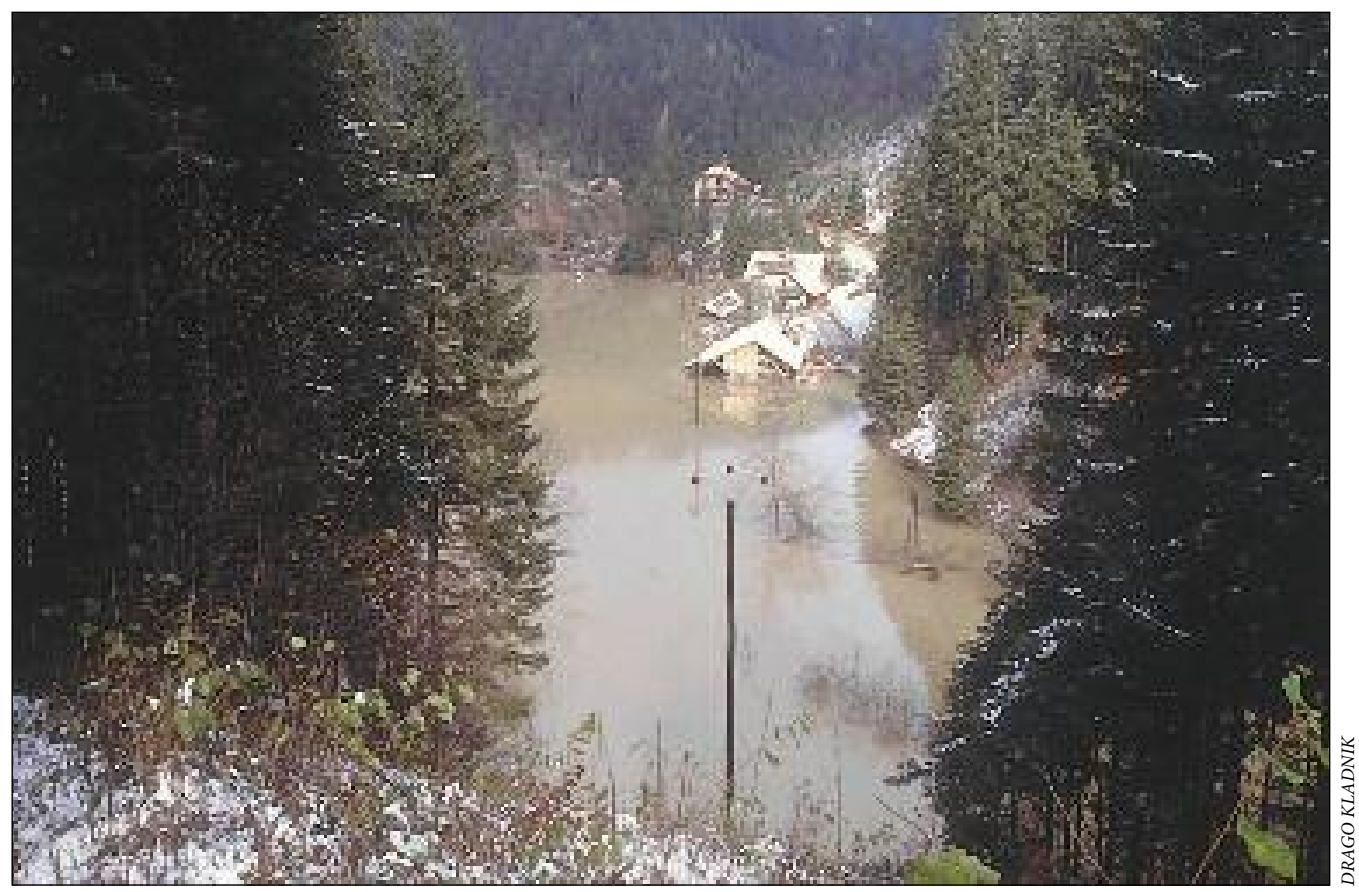

Slika 8: Plazovno jezero v Podvolovljeku, ki je nastalo med novembrskimi poplavami leta 1990. 
Plazovno jezero je nastalo tudi v Podvolovjeku leta 1990 (slika 8), ko je Tratičnikov plaz okrog $20 \mathrm{~m}$ na debelo in $200 \mathrm{~m}$ na široko zaprl pot Lučnici. V nekaj urah je nastalo 10 do $15 \mathrm{~m}$ globoko jezero, ki je segalo kilometer in pol po dolini navzgor. Lučnica je čez čas predrla pregrado in dvometrski poplavni val je razdejal del Luč v izteku doline (Komac, Natek in Zorn 2008).

Pri nas poznamo tudi nesreče zaradi porušitev umetnih jezov, ki pa so bile manjšega obsega. Na Pšati so ob regulacijah pri Mengšu zgradili jez. Ko se je 10. aprila 1968 porušil, je voda zalila 15 ha obdelovalnih zemljišč pri Jabljah, v Trzinu in Depali vasi (Radinja in ostali 1976). Ob poplavah Drave jeseni 1998 je v Dupleku popustil jez gramoznice, Drava je vdrla v naselje in v kratkem času poplavila kakšnih 350 hiš.

Poplavni val, sicer posredno povezan z obilnimi padavinami, lahko povzročijo tudi upravljavci hidroelektrarn. V začetku novembra 2012 je pretok Drave zaradi načrtno povečanega dotoka iz avstrijskih zajezitev dosegel najvišje izmerjene vrednosti (Kobold 2013). Posledična poplava je povzročila precejšno gmotno škodo (105 milijonov evrov), ki bi bila pri le naravnem pretoku za tretjino do polovico manjša (Ocena škode ... 2013).

\section{Pobočni procesi zaradi nihanja vodne gladine}

Pojavi nestabilnosti zaradi nihanja gladine nastajajo ob morskih obalah, naravnih in umetnih pregradah ter na obalah rek in kanalov.

Zemeljski plazovi se prožijo že ob gradnji umetnih jezov oziroma ob njihovem polnjenju, saj spremembe vodne gladine vplivajo na raven podtalnice in $s$ tem na stabilnost pobočij oziroma bregov. V pobočju se poveča porni tlak, zmanjša se natezna trdnost in lahko se pojavijo nestabilnosti. Do zdrsa običajno pride zaradi nenadnega padca gladine.

Takšni pojavi so znani iz časa gradnje Panamskega prekopa v Panami na začetku 20. stoletja, saj leži na plazovitem območju (Bommer in Rodríguez 2002). Zemeljski plazovi so spremljali že njegovo gradnjo. Zaradi nevarnosti plazenja so nenačrtovano premaknili 40 milijonov $\mathrm{m}^{3}$ gradiva, kar je toliko kot za 15 Keopsovih piramid. Prekop so z vodo napolnili leta 1913, a ga zaradi pogostega plazenja še leto dni niso odprli za promet (Alfaro 1988). Plovba je bila zaradi zemeljskih plazov močno otežena v letih 1931 in 1974, leta 1986 pa so ga skoraj zaprli za promet (Berman 1995).

$\mathrm{Na}$ Japonskem se je za umetnimi pregradami med letoma 1956 in 1997 sprožilo 20 zemeljskih plazov. Med gradnjo jezu Grand Coulee (slika 9) v ameriški zvezni državi Washington se je v nevezanih ledeniško-rečnih sedimentih med letoma 1941 in 1953 na obali Rooseveltovega jezera (slika 10) na reki Columbia sprožilo približno 500 zemeljskih plazov (Schuster 1979). Do podobnega pojava je prišlo tudi na Češkem v jezeru Nechranice. Pregrado so zgradili leta 1968, leto kasneje pa se je med nižanjem gladine jezera z $270 \mathrm{~m}$ na $252 \mathrm{~m}$ s hitrostjo $0,11-0,15 \mathrm{~m}$ na dan sprožilo več zemeljskih plazov. Zaradi plazenja se je obala ponekod spremenila za $50 \mathrm{~m}$.

Do nestabilnosti je prišlo tudi med polnjenjem jezer Orava na istoimenski reki na Slovaškem in Włocławek na reki Visli na Poljskem. Podobne primere poznamo iz Romunije, na primer zemeljski plaz, ki se je sprožil v akumulacijsko jezero Siriu (slika 11; Micu in Bălteanu 2013). Ob izjemni oseki v 40. letih prejšnjega stoletja je v pokrajini Zeeland na Nizozemskem morska gladina upadla za 2,8 do 4,6 m bolj kot običajno, zaradi česar so na obali nastali številni peščeni tokovi. Na jezeru Tablachaca v vzhodnem Peruju se je v 70. letih prejšnjega stoletja začel premikati fosilni kamniti zdrs in ogrozil $80 \mathrm{~m}$ visok jez. V Španiji sta se sprožila fosilna plazova v zajezitvi Cortes na reki Júcar (Rybáŕ, Stemberk in Wagner 2002).

\subsection{Vajontski zdrs}

Tudi v porečju Piave v Italiji je gradnja številnih jezov vplivala na geomorfne procese. Ker so doline na tem območju ozke, je večina plazov zasula dolinsko dno in nastala so naravna zajezitvena jezera. Najpomembnejši takšni pojavi so pri Fadaltu in Novi, pri Allegheju, Pra-Lagunazu in pri mestu Masiere de la Vedana. 
Blaž Komac, Matija Zorn Naravne in umetne pregrade ter $\mathrm{z}$ njimi povezani hidro-geomorfni procesi

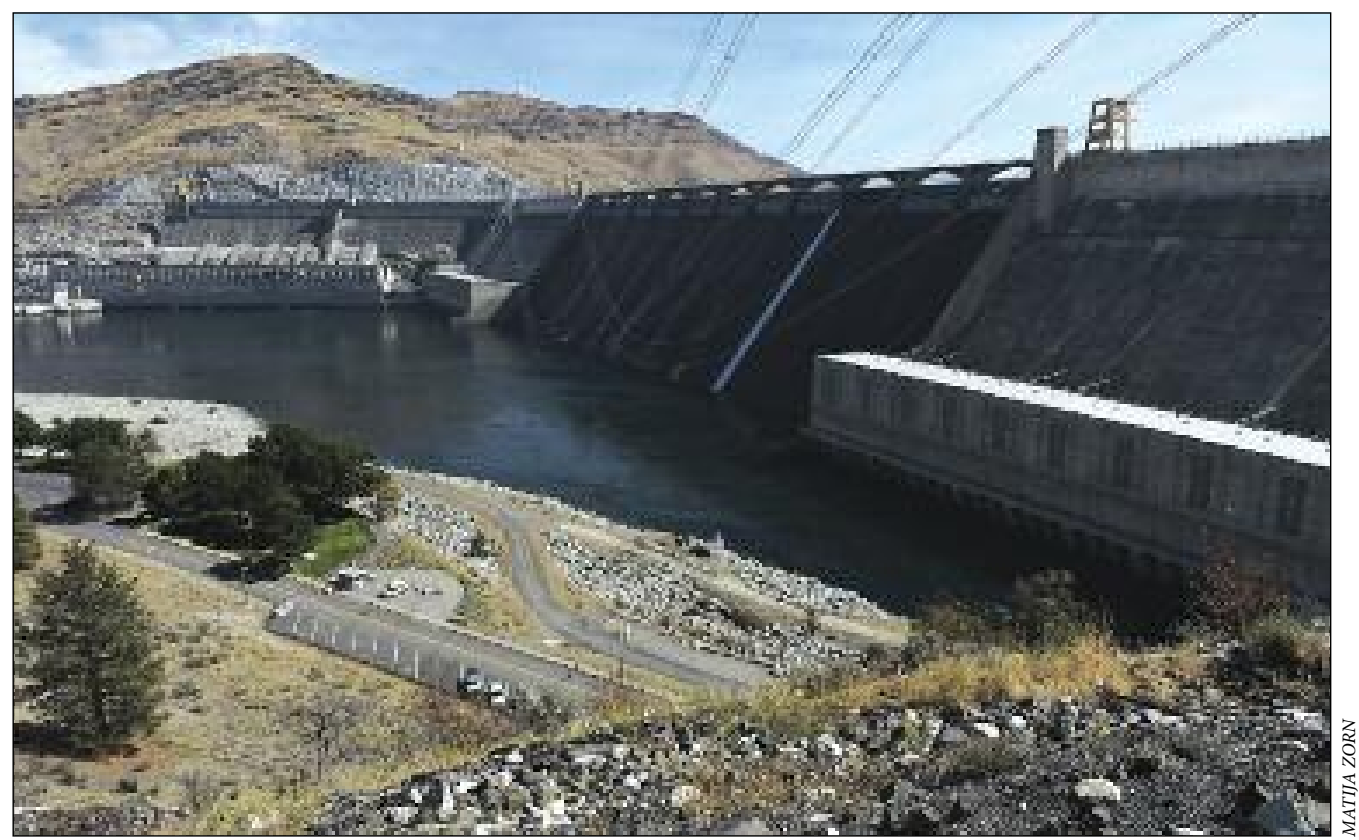

Slika 9: Jez Grand Coulee na reki Columbia v ameriški zvezni državi Washington so gradili med letoma 1933 in 1942. Jez je visok $168 \mathrm{~m}$ in dolg $1592 \mathrm{~m}$.

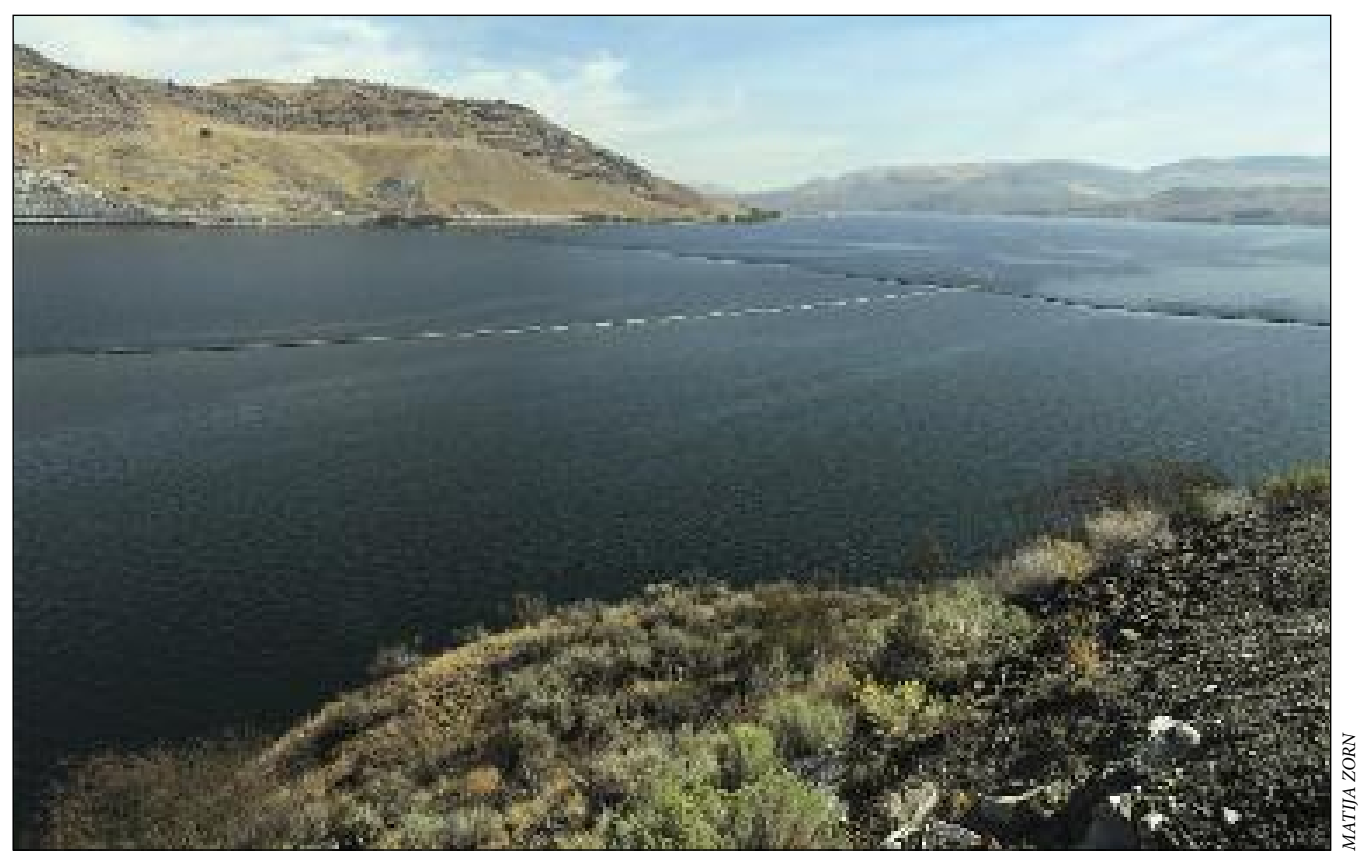

Slika 10: Umetno Rooseveltovo jezero na reki Columbia v ameriški zvezni državi Washington ima površno $324 \mathrm{~km}^{2}$. 

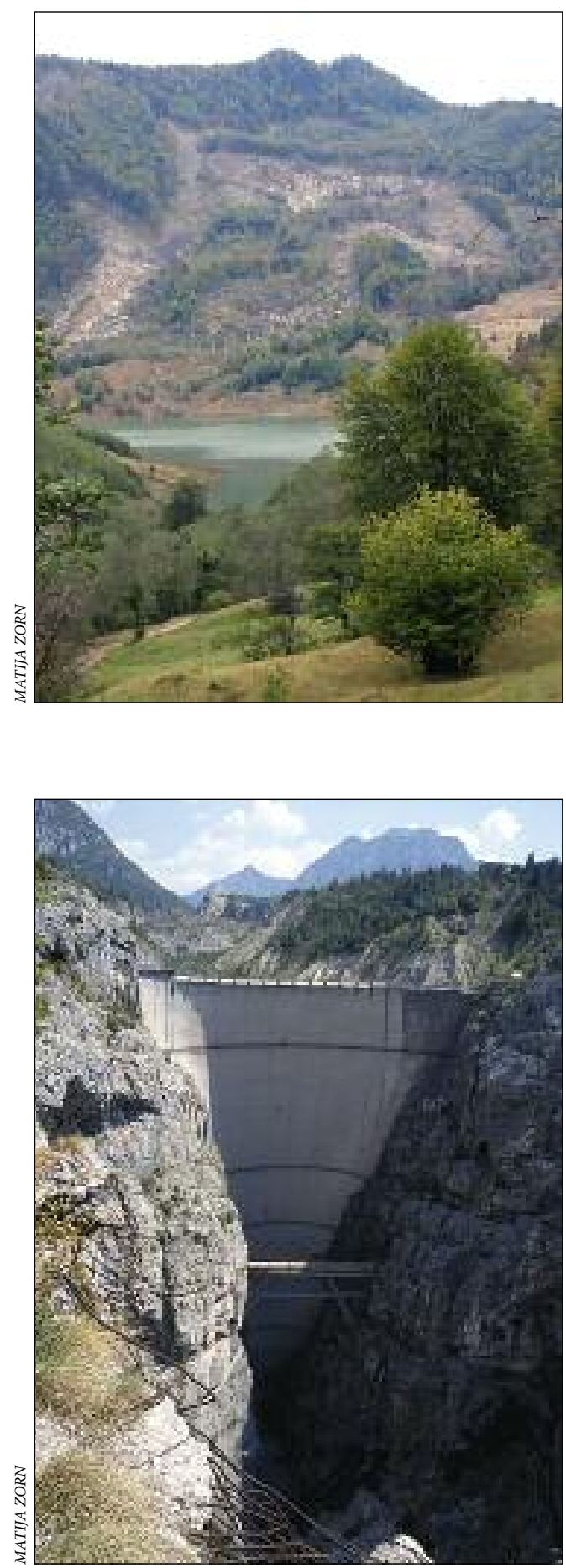

Slika 11: Devet milijonov $\mathrm{m}^{3}$ velik zemeljski plaz se je sprožil v umetno jezero Siriu $v$ romunskih Karpatih.

Slika 12: Pregrada v dolini Vajont. Za pregrado je vidna odložena gmota kamnitega zdrsa, poraščena $z$ drevjem. 
Verjetno najbolj znana katastrofa Evropi, povezana s pobočnim procesom, ki se je sprožil v umetno jezero, je vajontski zdrs (Barla in Paronuzzi 2013; Genevois in Tecca 2013; ime smo poslovenili, sicer pa je tudi furlansko ime za dolino Vajont, italijansko ime je Vaiont). O dogodku in posledicah obstaja obsežna literatura (glej Supechi in ostali 2010; The Vaiont ... 2010; The Vajont ... 2013).

Porečji Piave in Tilmenta sta zaradi bližine Jadranskega morja in velikih relativnih višinskih razlik podvrženi intenzivnim hidro-geomorfnim procesom. Reke na tem območju imajo hudourniški značaj zaradi obilice padavin. Prva razmišljanja o hidroenergetski izrabi in »umiritvi« rečnih tokov so se pojavila že na začetku 20. stoletja, v petdesetih in šestdesetih letih pa so za potrebe hitro rastočih severnoitalijanskih mest zgradili hidroenergetski sistem s sedmimi akumulacijskimi jezeri in osmimi elektrarnami (Natek 1999).

Vajontska nesreča je med gradbeniki znana po tem, da je betonska konstrukcija jezu zdržala velike napetosti in visoki jez lahko občudujemo še danes (slika 12), le da za njim ni jezera temveč plazovina.

261,6 m visok betonski jez so v ozki dolini zgradili septembra leta 1960 kot del velikega hidroenergetskega sistema v porečju Piave. Takrat je bil to najvišji jez na svetu. Prvi načrti za gradnjo segajo že v leto 1900, dela pa so stekla leta 1956 (Zorn 2003/2004).

Dolina Vajont ima sinklinalno geološko zgradbo, tako da kamninske plasti na severnih in južnih pobočjih vpadajo proti dolinskemu dnu, kar je ugodno za nastanek kamnitih zdrsov. Pobočja nad dolino sestavljajo apnenci jurske in triasne starosti, med katerimi so tanjše glinene plasti. Dolino so v ledenih dobah preoblikovali ledeniki. Na začetku holocena so se pobočja delno stabilizirala s pobočnimi procesi (Zorn 2003/2004; Wolter in ostali 2016, 1079).

Že med gradnjo jezu so na desnem pobočju našli sledi starega zdrsa. Kljub temu so domnevali, da so zdrsi večjih razsežnosti malo verjetni, čeprav manjših niso izključili. Februarja 1960 so še pred dokončanjem jezu začeli s polnjenjem jezera. Marca 1960, ko je na pobočjih nad jezerom prišlo do prvih nestabilnosti, je bilo umetno jezero globoko $130 \mathrm{~m}$. Oktobra istega leta je bila globina jezera $170 \mathrm{~m}$. Takrat so južna pobočja polzela s hitrostjo približno $3,5 \mathrm{~cm} /$ dan, nastala je tudi $2,5 \mathrm{~km}$ dolga razpoka. 4 . novembra 1960, ko so gladino jezera dvignili na $180 \mathrm{~m}$, je nastal kamniti zdrs. V približno desetih minutah v jezero zdrselo okrog $700.000 \mathrm{~m}^{3}$ gradiva; nastal je poplavni val višine $2 \mathrm{~m}$ (Zorn 2003/2004).

Po tem dogodku so znižali gladino jezera, da je imelo globino $135 \mathrm{~m}$. S tem se je polzenje zmanjšalo na $1 \mathrm{~mm} /$ dan. Pristojni so domnevali, da lahko drsenje obvladujejo z nadzorovanim spreminjanjem gladine jezera. Zato so oktobra 1961 zopet začeli dvigati gladino in februarja 1962 dosegli relativno višino $185 \mathrm{~m}$, novembra 1962 pa $235 \mathrm{~m}$. Ob dviganju gladine se polzenje pobočij sprva ni bistveno spremenilo, sčasoma pa se je hitrost povečala na $1,5 \mathrm{~cm} /$ dan. Novembra 1962 so zopet začeli spuščati gladino in v naslednjih štirih mesecih dosegli raven $185 \mathrm{~m}$, premikanje pobočij se je skoraj ustavilo (Semenza in Ghirotti 2000; Zorn 2003/2004; Majhen 2016, 45).

Sledil je še tretji dvig ravni jezera. Maja 1963 so dosegli raven $231 \mathrm{~m}$, pri čemer so pobočja polzela s hitrostjo $0,3 \mathrm{~cm} /$ dan. Junija so raven dvignili na $237 \mathrm{~m}$, hitrost polzenja pobočij pa se je povečala na $0,4 \mathrm{~cm} /$ dan. Ko so julija dosegli raven $240 \mathrm{~m}$, je bila hitrost $0,5 \mathrm{~cm} /$ dan, avgusta pa se je povečala na $0,8 \mathrm{~cm} /$ dan. Septembra so dosegli raven $245 \mathrm{~m}$, polzenje pobočij se je povečalo na $3,5 \mathrm{~cm} / \mathrm{dan}$. Sledilo je počasno spuščanje gladine jezera. 9 . oktobra 1963 je bila globina jezera na $235 \mathrm{~m}$, hitrost polzenja pa je bila do $20 \mathrm{~cm} /$ dan (Zorn 2003/2004).

Tega dne se je ob 22:38 sprožil 1,8 km dolg in 1,6 km širok kamniti zdrs (slike 13-16). Jezero je imelo približno 115 milijonov $\mathrm{m}^{3}$ vode. Ko je ogromna gmota zdrsela vanj, je nastal velik val ( 50 milijonov $\mathrm{m}^{3}$ ), ki je potoval po jezero gorvodno in dolvodno (slika 14). Na nasprotni strani doline je segel do $260 \mathrm{~m}$ nad raven gladine jezera in poplavil vas Casso. Prek pregrade se je proti dolini Piave izlilo 25-30 milijonov $\mathrm{m}^{3}$ vode. Sedemdeset metrski poplavni val je 500 višinskih metrov niže uničil naselja Longarone (sliki 17 in 18), Pirago, Villanova, Rivalta in Faé (preglednica 1) ter segal še 2 do 2,5 km po dolini Piave navzgor. Reka je bila še $60 \mathrm{~km}$ po toku navzdol visoka $12 \mathrm{~m}$. Betonski jez je ob tem dogodku ostal skoraj nepoškodovan (slika 12). Tudi val, ki je potoval gorvodno po jezeru, je poplavil nekaj vasi. Cel dogodek je trajal le sedem minut, terjal pa je več kot 2000 žrtev (Semenza 2001). 


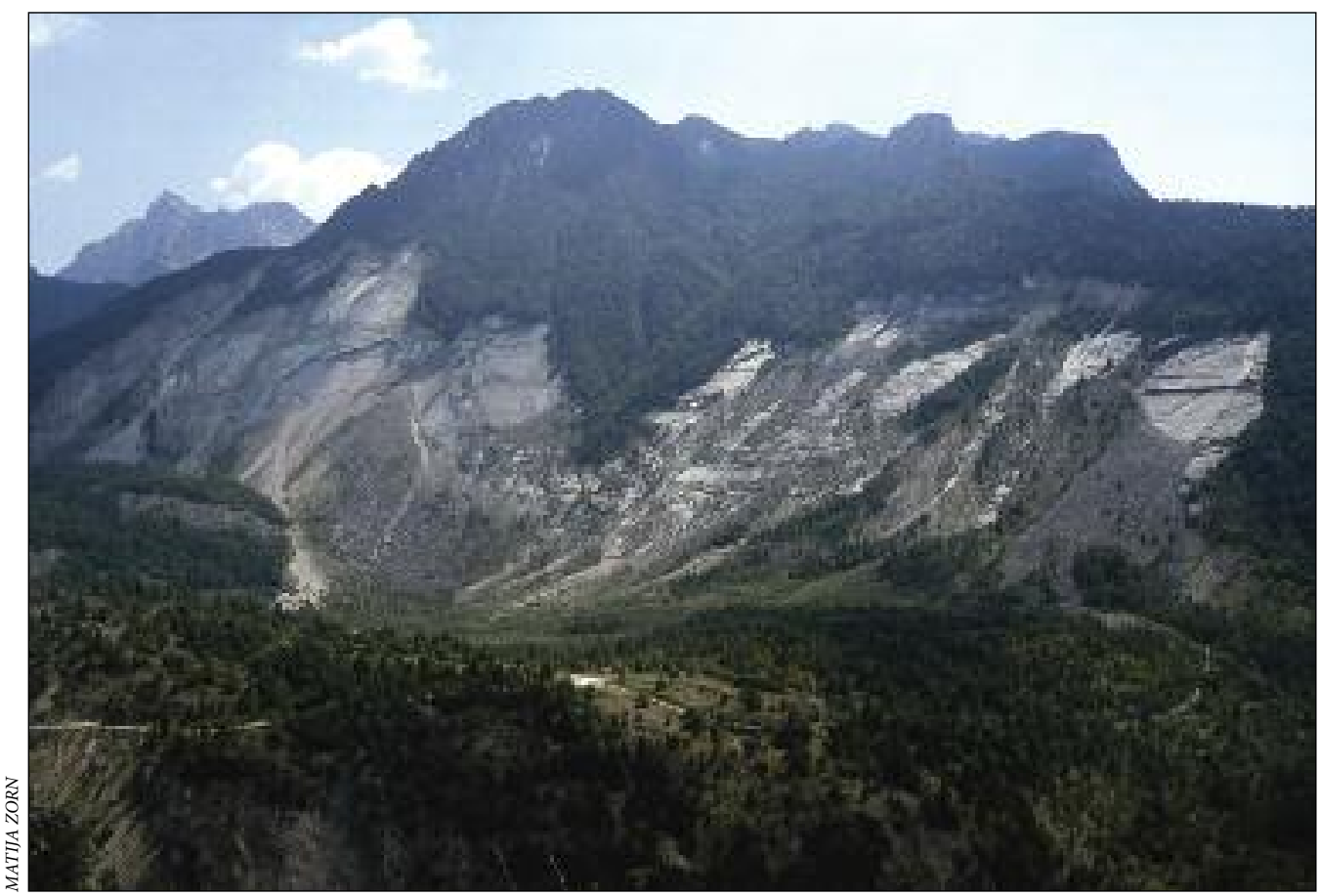

Slika 13: Odlomna ploskev kamnitega zdrsa na pobočju gore Toc je dolga 1,8 km in široka 1,6 km. $V$ spodnjem delu slike je z gozdom poraščena odložena gmota kamnitega zdrsa.

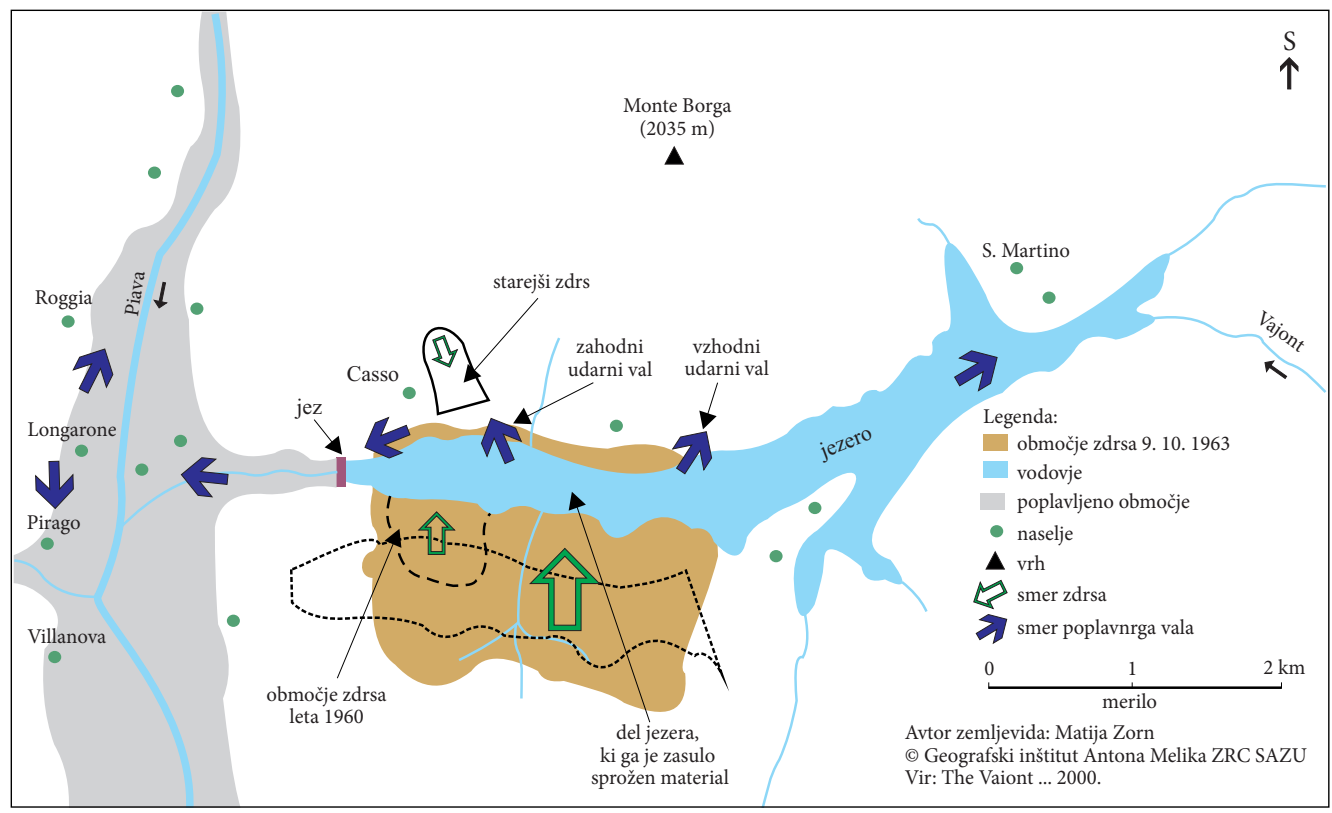

Slika 14: Kamniti zdrs in poplavni val v dolini Vajont (Zorn 2003/2004, 247.) 
Blaž Komac, Matija Zorn Naravne in umetne pregrade ter z njimi povezani hidro-geomorfni procesi

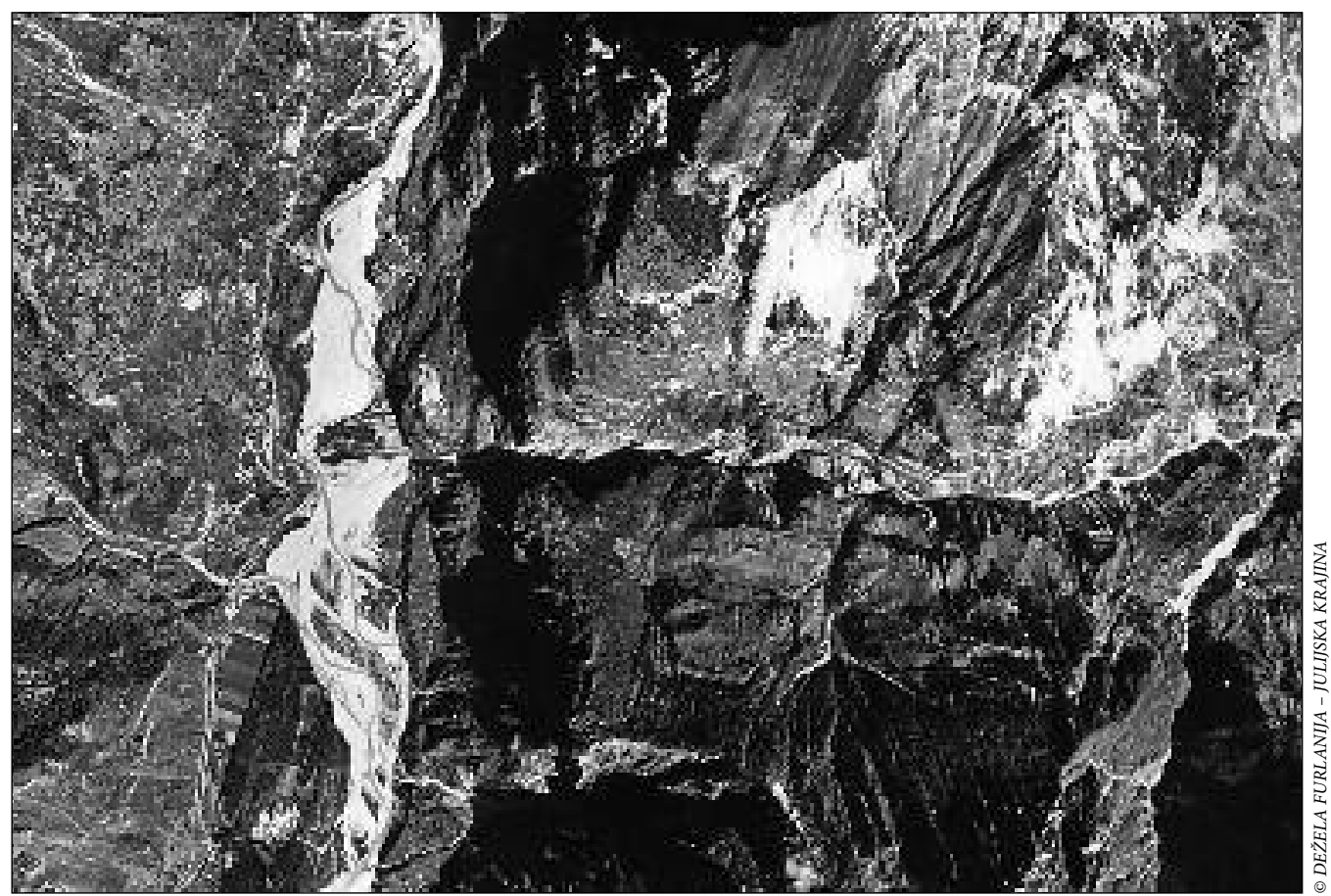

Slika 15: Letalski posnetek doline Vajont iz leta 1954 - pred sprožitvijo kamnitega zdrsa.

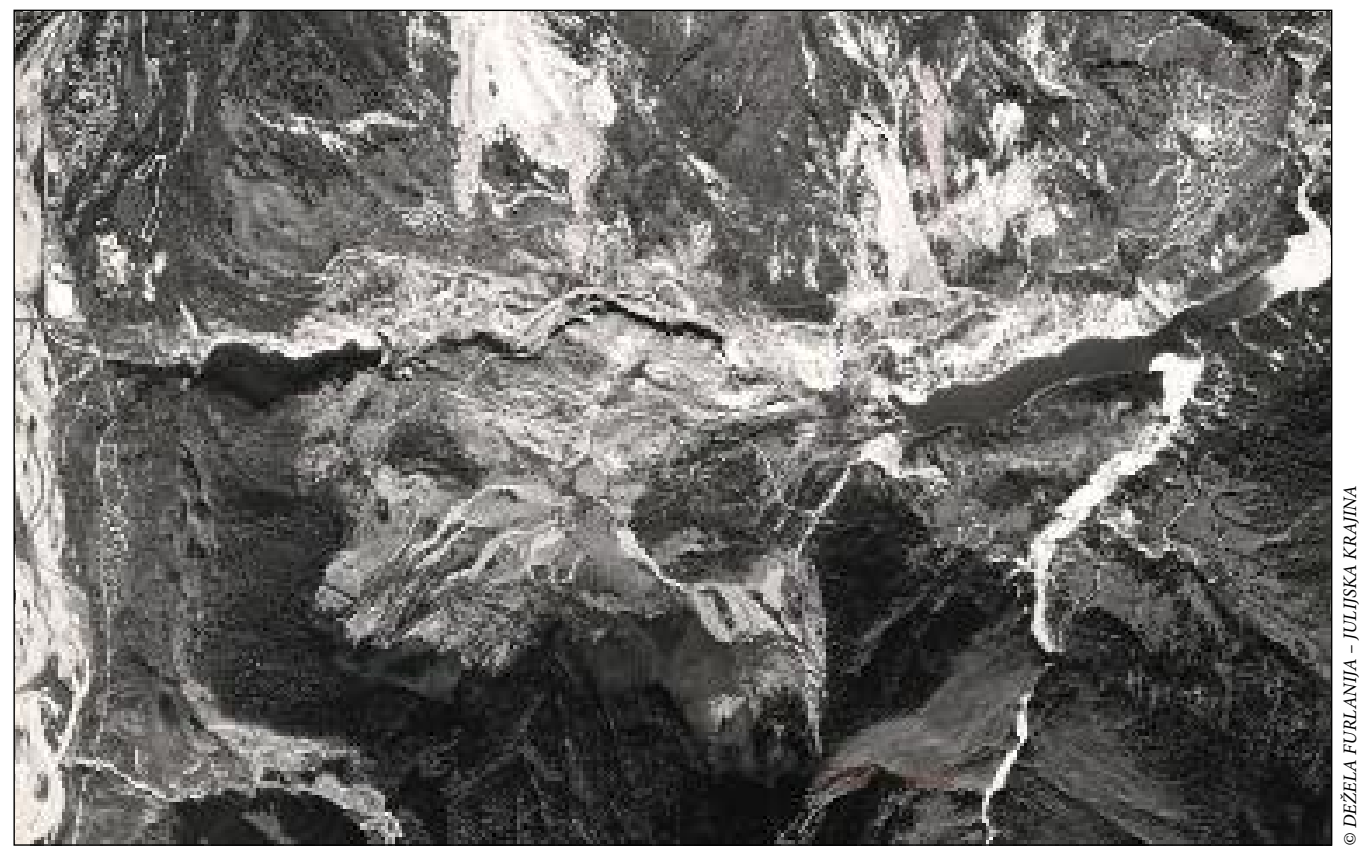

Slika 16: Letalski posnetek doline Vajont iz leta 1984 - po sprožitvi kamnitega zdrsa. 


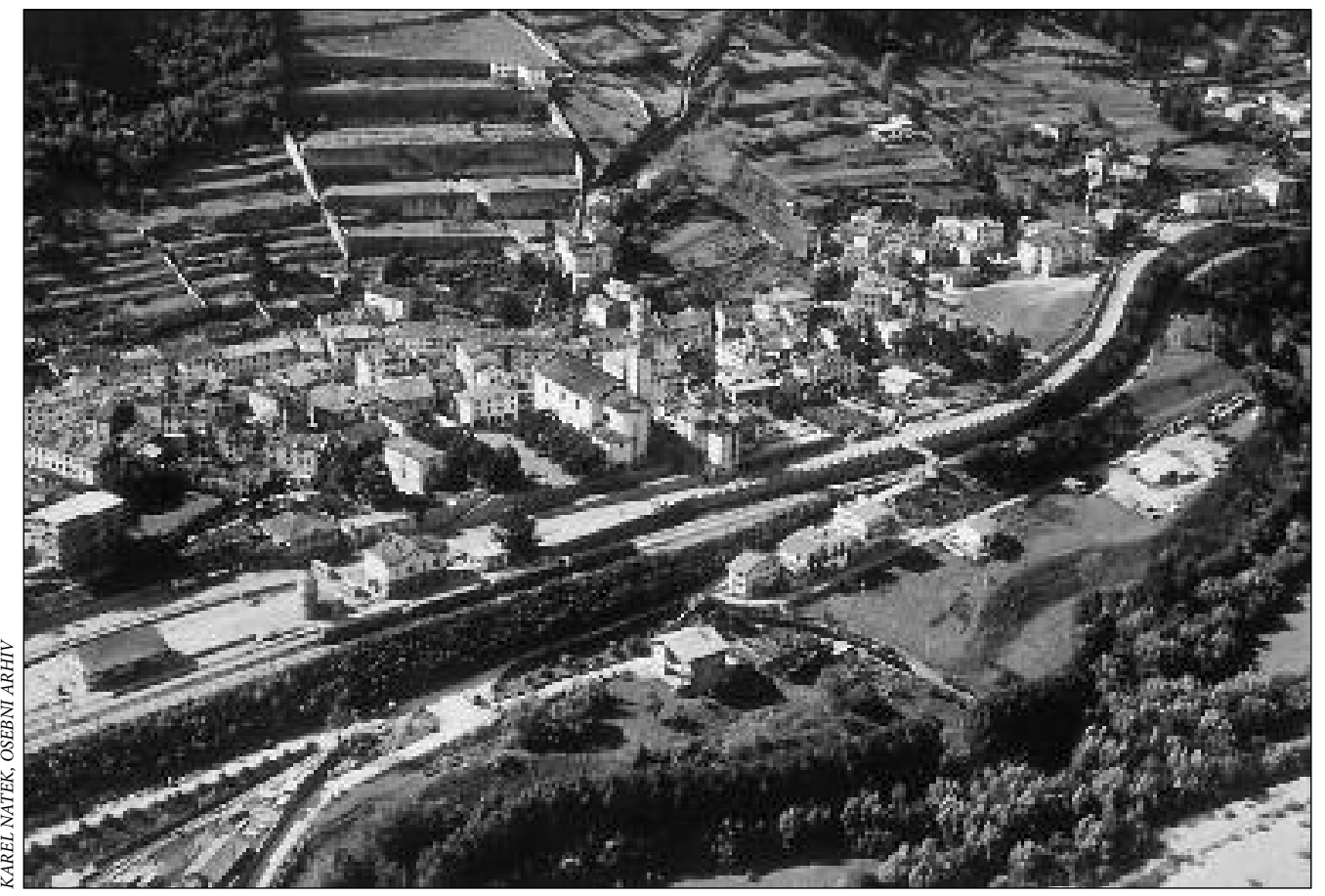

Slika 17: Longarone pred poplavnim valom.

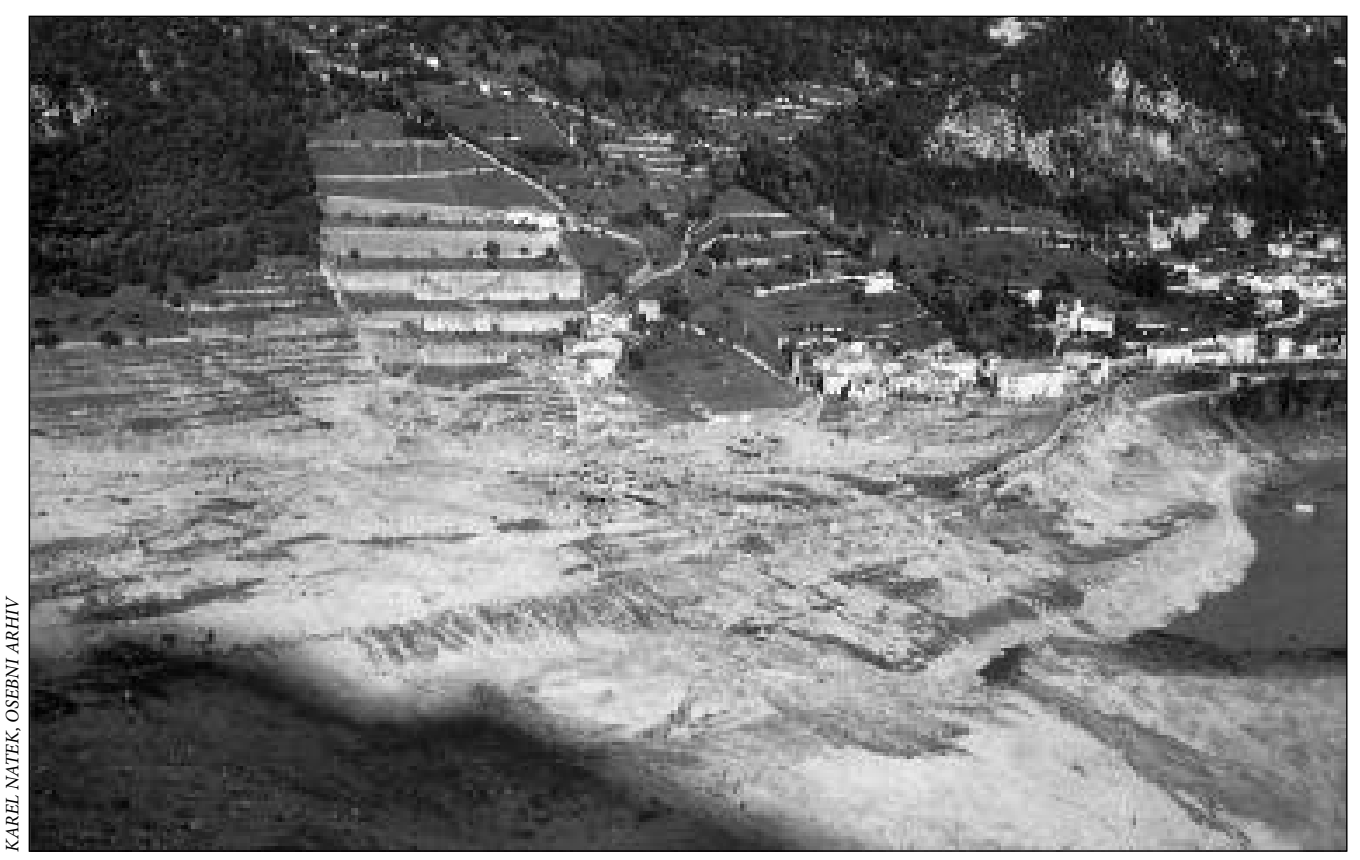

Slika 18: Longarone po poplavnem valu. 
Zdrs je nastal v 5-15 cm debelih glinenih plasteh v apnencu $\mathrm{z}$ montmorillonitno glino, kar je potrdila šele raziskava sredi 80. let prejšnjega stoletja (Hendron in Patton 1987). Poleg dviganja gladine jezera so k sprožitvi prispevale tudi obilne septembrske padavine, ki so dodatno obremenile pobočja nad jezerom (Semenza 2001; Zorn 2003/2004).

Preglednica 1: Število stavb pred nesrečo in število uničenih stavb (Semenza 2001; Disastro ... 2016).

\begin{tabular}{lccc}
\hline & število stavb pred nesrečo & število uničenih stavb & delež uničenih stavb (\%) \\
\hline Longarone & 372 & 361 & 97 \\
Pirago in Rivalta & 159 & 159 & 100 \\
Villanova in Faé & 59 & 32 & 54 \\
skupaj & 590 & 552 & 94 \\
\hline
\end{tabular}

\section{Porušitve umetnih pregrad}

Podatki o številu umetnih pregrad po svetu se razlikujejo. Po podatkih Svetovne komisije za jezove (Dams ... 2000, 9) je bilo na svetu do začetka 20. stoletja zgrajenih nekaj sto večjih pregrad. Do srede 20. stoletja je bilo takšnih že okrog 5000, do konca stoletja pa je število preseglo 45.000. Zgrajene so v prek 140 državah. Bergström (1990) navaja, da je na svetu blizu tisoč jezov, ki so višji od $15 \mathrm{~m}$ in zadržujejo vsaj 500 milijonov $\mathrm{m}^{3}$ vode. Fuggle in Smith (2000) pišeta, da je samo na Kitajskem več kot 85.000 »večjih« jezov ter ocenjujeta, da je »manjših« več milijonov. Po Rangachariju in ostalih (2000) je v Indiji je več kot 4000 »večjih « jezov, Malik in ostali (2000) pa ocenjujejo, da je v Rusiji približno 2000 »večjih« jezov.

V Sloveniji je 47 pomembnejših pregrad. V Primorju so tri, v Posočju štiri, v Posavju sedem, v Pomurju osem, $\mathrm{v}$ Podravju enajst in $\mathrm{v}$ Posavinju trinajst. Med njimi je le ena $\mathrm{z}$ majhno do srednjo nevarnostjo za porušitev, $40 \%$ je srednje nevarnih, $46 \%$ srednje do visoko nevarnih, desetina pa je visoko nevarnih. Najbolj nevarne so pregrade v Posočju (ocena 4,5 na lestvici od 1 do 5 , kjer 5 pomeni najvišjo nevarnost), sledijo Posavje $(3,9)$, Primorje $(3,7)$ ter enako ocenjene regije Posavinje, Pomurje in Podravje $(3,5)$ (preračunano po Kryžanowskem in ostalih 2012).

Pri vsaki umetni zajezitvi je mogoča porušitev pregrade. Samo na zahodu Združenih držav Amerike se je v obdobju 1990-2008 porušilo 566 jezov (National ... 2008). Pogosto so v nevarnosti naselja, saj pri porušenju nastane hiter in visok poplavni val. Razlita voda povzroča zaradi velike energije tudi veliko škode in erozijo. Nekatera območja zato postanejo neprimerna za kmetijsko dejavnost ali bivanje. Ta pojav so zato izkoriščali v vojaške namene (Zorn in Komac 2009).

Jezovi se pogosto porušijo zaradi povečanega dotoka vode ob neurjih. Januarja 1959 se je po obilnem deževju porušil 34 metrov visok betonski jez v Vega de Tera v Španiji. Osem milijonov $\mathrm{m}^{3}$ vode je po 20 minutah uničilo $5 \mathrm{~km}$ oddaljeno naselje Rivaldelago, v katerem je umrlo 144 ljudi. Jez se je podrl zaradi šibkosti na stiku z bregovi. V Argentini se je ob neurju januarja 1970 podrl 15 metrov visok kamnito-betonski jez na reki Mendoza. Dvometrski poplavni val je uničil domove 500 ljudi v bližnjem mestu; umrlo je 40 ljudi (Bergström 1990, 39-40). Avgusta 1975 je ob tajfunu v kitajski provinci Henan $\mathrm{v}$ treh dneh padlo $1605 \mathrm{~mm}$ padavin, zaradi česar se je porušil jez Banqiao na reki Ruhe. Poplavljenih je bil milijon hektarov zemljišč, več kot $100 \mathrm{~km}$ železniške proge Peking-Guangzhou, umrlo je več kot 20.000 ljudi. Leta 1993 je ob porušitvi betonskega jezu Gouhou v isti provinci umrlo 1200 ljudi (Fuggle in Smith 2000). Ob tropskem ciklonu Alberto leta 1994 se je v ameriški zvezni državi Georgija porušilo 200 povečini manjših jezov (Wahl 1998). 6. novembra 1977 se je ob obilnih padavinah podrl jez Kelly Barnes v isti ameriški zvezni državi. V poplavi z najvišjim pretokom približno $7300 \mathrm{~m}^{3} / \mathrm{s}$ je umrlo 39 ljudi 
(Toccoa ... 2016). Septembra 1985 se je na reki Öre na Švedskem podrl 16 m visok zemeljski jez. V 45 minutah so odtekli trije milijoni $\mathrm{m}^{3}$ vode. Vodni tok s pretokom velikostnega reda $1000 \mathrm{~m}^{3} / \mathrm{s}$ je v dolžini dva kilometra izdolbel novo strugo. Do porušitve je prišlo, potem ko se je ob obilnih padavinah zamašil talni odtok iz jezera (Bergström 1990, 39-40).

Jezovi se lahko porušijo tudi zaradi potresov. Leta 1925 se je ob potresu porušil jez Sheffield severno od naselja Santa Barbara v Združenih državah Amerike. 200 metrov dolg in 7,5 m visok jez iz zemlje so zgradili leta 1917. Ob potresu je prišlo do utekočinjenja materiala, ki je gradil jez. Voda je povzročila le gmotno škodo in poplavila spodnji del mesta (The 1925 ... 2008).

Za številne porušitve ne poznamo povoda, temveč gre za preplet različnih vzrokov. Decembra 1976 se je porušil 66 metrov visok jez na reki Revan. 22 milijonov $\mathrm{m}^{3}$ vode je na poti do Sredozemskega morja uničilo mesto Fréjus v Franciji, umrlo je 421 ljudi (Bergström 1990). Leta 2002 se je podrl jez Zeyzoun v severni Siriji. Odteklo je približno 71 milijonov $\mathrm{m}^{3}$ vode, ki je poplavila $8000 \mathrm{~km}^{2}$ zemljišč v okolici naselij Zeyzoun, Qastoun, in Ziara $350 \mathrm{~km}$ severno od Damaska. Umrlo je 20 ljudi, na tisoče jih je ostalo brez domov (Dam Break in Syria ... 2016). Marca 2004 se je podrl 15 m visok zemeljski jez na reki Bay Creek v ameriški zvezni državi Misisipi. Petmetrski poplavni val je porušil več kot sto stavb (Yochum, Goertz in Jones 2008). Decembra 2005 se je na podnožju Profit Mountain v Združenih državah Amerike porušil $30 \mathrm{~m}$ visok jez, ki so ga leta 1963 zgradili iz kamenja. Jez je bil obdan še z betonom in asfaltom (Vries 2005). Marca 2006 se je porušil jez na reki Kauai na Havajih. Po dolini je odteklo $2000 \mathrm{~m}^{3}$ vode; umrlo je več ljudi (Dam break brings ... 2008). Na reki Snake v ameriški zvezni državi Idaho se je zaradi napake pri načrtovanju junija 1976 ob prvem polnjenju podrl 93 metrov visok jez iz zemlje; odteklo je 300 milijonov $\mathrm{m}^{3}$ vode. Bilo je »le« enajst žrtev, ker so prebivalce spodaj ležečih naselij pravočasno posvarili pred nevarnostjo (Bergström 1990).

\section{Sklep}

Pobočni procesi lahko ustvarijo naravne pregrade, za katerimi se v ozkih dolinah zbere veliko vode. Takšni dogodki so v vzpetem svetu relativno pogosti, a mnogokrat neopaženi, saj lahko v razmeroma kratkem času pride do prelitja ali porušitve pregrad.

Večji dogodki pustijo v pokrajini sledi; na primer naravna pregrada ima lahko sama po sebi krajevni značaj in povzroči manjšo škodo, s podrtjem pa lahko povzroči poplave regionalnih razsežnosti (Bonnard 2011). Pogosto so to tako veliki pojavi, da jim nismo kos niti s sodobno tehnologijo. Podobne poplave lahko povzročijo tudi porušitve umetnih pregrad.

Regionalni zemeljski plazovi in skalni podori so v holocenu sicer manj pogosti kot so bili ob koncu pleistocena, ko so bili povezani z otoplitvijo podnebja. Njihov nastanek je v sodobnosti povezan predvsem s potresi. V zadnjih stoletjih in tudi desetletjih smo bili predvsem v zahodni Sloveniji in zamejstvu priča močnejšim potresom, ki so povzročili pobočne procese. Takšni dogodki lahko močno vplivajo na življenje prebivalcev oziroma prožnost družbe. Pogosto so negativni, lahko pa tudi pozitivni, saj so naravne »jezove« ponekod po svetu izkoristili za hidroenergetsko izrabo.

Že »srednje« močan potres, kot je bil aprila 1998 v Posočju, je povzročil približno sto skalnih podorov, ki so se na srečo povečini sprožili v nenaseljenih ali odmaknjenih predelih (Komac 2015); gradivo je "pristalo« tudi v Soči. Kljub temu je bilo Bovško dan in pol po potresu dostopno le po dolini Učje; pri Trnovem ob Soči je cesto zapiral skalni odlom, na Vršiču in Predelu pa sneg. Podobno je bilo ob drobirskem toku v Logu pod Mangartom leta 2000, ko je bila mednarodna prometnica čez Predel zaprta več kot četrt leta (Komac in Zorn 2007).

V Sloveniji obpotresni pobočni procesi, ki lahko zajezijo vodotoke, nastanejo predvsem v gorskih in hribovitih pokrajinah (Komac 2015). Takšnih pojavov zaradi velikosti ne moremo preprečiti niti zmanjšati njihove moči oziroma učinkov na pokrajino, posebej na njene družbene prvine (naselja, prometnice). Velja pa tudi obratno. Prebivalci se sami težko pripravijo na takšno nevarnost. Ker pa je zaradi 
velike nevarnosti za prebivalce nesprejemljivo, da bi takšne pojave in njihov razvoj le opazovali, je ob njihovem nastanku nujno takojšnje ukrepanje, kar smo lahko opazovali na Kitajskem po omenjenem potresu leta 2008, ko so se nemudoma lotili odstranjevanja gradiva. Kjer je to smiselno, pa je treba razmišljati in tudi uvesti preventivne ukrepe, kot so sodobni opazovalni sistemi ter gradnja podornih galerij in predorov.

\section{Viri in literatura}

Alfaro, L. D. 1988: The risk of landslides in Gaillard Cut. Poročilo, Panama Canal Comission, Engineering Division, Geotechnical Branch. Balboa Heights. Medmrežje: http://www.pancanal.com/esp/ plan/estudios/ep-0008.pdf (11.10.20016).

Barla, G., Paronuzzi, P. 2013: The 1963 Vajont landslide: 50th anniversary. Rock Mechanics and Rock Engineering 46-6. DOI: http://dx.doi.org/10.1007/s00603-013-0483-7

Bergström, M. 1990: The release in war of dangerous forces from hydrological facilities. Environmental Hazards of War. London.

Berman, G. 1995: Landlides of the Panama Canal. Energy and Mineral Potential of the Central American-Carribean Region. Circum-Pacific Council for Energy and Mineral Resources Earth Science Series 16. Berlin, Heidelberg. DOI: http://dx.doi.org/10.1007/978-3-642-79476-6_53

Bizjak, R. 2011: Idrija na prelomu 16. stoletja. Idrijski razgledi 56-1.

Bommer, J. J., Rodríguez, C. E. 2002: Earthquake-induced landslides in Central America. Engineering Geology 63, 3-4. DOI: http://dx.doi.org/10.1016/S0013-7952(01)00081-3

Bonnard, C. 2011: Technical and human aspects of historic rockslide-dammed lakes and landslide dam breaches. Natural and Artificial Rockslide Dams. Berlin. DOI: http://dx.doi.org/10.1007/ 978-3-642-04764-0_3

Cecić, I. 2011: Idrijski potres 26. marca 1511: Kaj pravzaprav vemo o njem? Geografski obzornik 58-1.

Costa, J. E., Schuster, R. L. 1988: The formation and failure of natural dams. Geological Society of America Bulletin 100-7. Boulder. DOI: http://dx.doi.org/10.1130/0016-7606(1988)100<1054:TFAFON>2.3.CO;2

Costa, J. E., Schuster, R. L. 1991: Documented Historical Landslide Dams from Around the World. U. S. Geological Survey Open-File Report 91-239. Vancouver. Medmrežje: http://pubs.usgs.gov/of/1991/ 0239/report.pdf (11.10.20016).

Czoernig, C. v. 1876: Über die in der Grafschaft Görz seit Römerzeiten vorgekommenen Veränderungen der Flussläufe. Der Isonzo, als der jüngste Fluss von Europa. Mitteilungen der k. k. Geographischen Gesellschaft in Wien 19.

Dams and Development: A New Framework. The report of the World Commission on Dams. London, 2000. Medmrežje: http://www.unep.org/dams/WCD/report/WCD_DAMS\%20report.pdf(11. 10.2016).

Dam Breach, Dam Failure, and Flooding Links. U.S. Department of the Interior. Bureau of Reclamation. Medmrežje: http://www.usbr.gov/pmts/hydraulics_lab/twahl/breach/breach_links.html (1.7.2008).

Dam Break Brings »Niagara Falls« to Hawaii Valley. CNN, 16.3.2006. Medmrežje: http://edition.cnn.com/ 2006/US/03/15/hawaii.dam/ (30.6.2008).

Dam Break in Syria. NASA Earth observatory. Medmrežje: http://earthobservatory.nasa.gov/IOTD/ view.php?id=2508 (11.10.2016).

Diakon, P. 1988: Zgodovina Langobardov. Maribor.

Disastro del Vajont - Diga del Vajont (9. ottobre 1963). Medmrežje: http://www.vajont.net (11. 10. 2016).

Evans, S. G., Delaney, K. B., Hermanns, R. L., Strom, A., Scarascia-Mugnozza, G. 2011a: The formation and behaviour of natural and artificial rockslide dams; Implications for engineering performance and hazard management. Natural and Artificial Rockslide Dams. Lecture Notes in Earth Sciences 133. Berlin. DOI: http://dx.doi.org/ 10.1007/978-3-642-04764-0_1 
Evans, S. G., Hermanns, R. L., Strom, A., Scarascia-Mugnozza, G. (ur.) 2011b: Natural and Artificial Rockslide Dams. Lecture Notes in Earth Sciences 133. Berlin. DOI: http://dx.doi.org/10.1007/9783-642-04764-0

Fan, X., van Westen, C. J., Xua, Q., Gorum, T., Dai, C. 2012: Analysis of landslide dams induced by the 2008 Wenchuan earthquake. Journal of Asian Earth Sciences 57-5. DOI: http://dx.doi.org/10.1016/ j.jseaes.2012.06.002

Fuggle, R., Smith, W. T. 2000: Large Dams in Water and Energy Resource Development in the People's Republic of China (PRC). World Commission on Dams. Cape Town.

Genevois, R., Tecca, P. R. 2013: The Vajont landslide: state-of-the-art. Italian Journal of Engineering Geology and Environment - Book Series 6: International Conference on Vajont - 1963-2013 Thoughts and Analyses After 50 Years Since the Catastrophic Landslide. Padua. DOI: http://dx.doi.org/ 10.4408/IJEGE.2013-06.B-02

Grimšičar, A. 1988: Zemeljski plazovi v Sloveniji: I. zgodovina. Ujma 2.

Handron, A. J., Patton, F. D. 1987: The Vaiont slide: A geotechnical analysis based on new geologic observations of the failure surface. Engineering Geology 24. DOI: http://dx.doi.org/10.1016/ 0013-7952(87)90080-9

Jesenovec, S. (ur.) 1995: Pogubna razigranost - 110 let organiziranega hudourničarstva na Slovenskem 1884-1994. Ljubljana.

Kobold, M. 2013: Poplave konec oktobra in v začetku novembra 2012. Ujma 27.

Komac, B. 2015: Modeliranje obpotresnih pobočnih procesov v Sloveniji. Geografski vestnik 87-1. DOI: http://dx.doi.org/10.3986/GV87107

Komac, B., Natek, K., Zorn, M. 2008: Geografski vidiki poplav v Sloveniji. Geografija Slovenije 20. Ljubljana.

Komac, B., Zorn, M. 2008: Pobočni procesi in človek. Geografija Slovenije 15. Ljubljana.

Komac, B., Zorn, M. 2009: Pokrajinski učinki skalnega podora v Pologu. Geografski vestnik 81-1.

Korup, O. 2002: Recent research on landslide dams-a literature review with special attention to New Zealand. Progress in Physical Geography 26-2. DOI: http://dx.doi.org/10.1191/0309133302pp333ra

Korup, O., McSaveney, M. J., Davies, T. R. H. 2004: Sediment generation and delivery from large historic landslides in the Southern Alps, New Zealand. Geomorphology 61, 1-2. DOI: http://dx.doi.org/ 10.1016/j.geomorph.2004.01.001

Kryžanowski, A., Širca, A., Humar, N., Ravnikar Turk, M., Žvanut, P., Četina, M., Rajar, R., Detela, I., Polič, M. 2012: Zemeljske in betonske vodne pregrade strateškega pomena v RS - VODPREG. Raziskovalno poročilo, Zavod za gradbeništvo Slovenije. Ljubljana.

Kuščer, D., Grad, K., Nosan, A., Ogorelec, B. 1974: Geološke raziskave soške doline med Bovcem in Kobaridom. Geologija 17.

Majhen, M. 2016: Inženirska tragedija 20. stoletja. Življenje in tehnika 67-9.

Malik, L. K., Koronkevich, N. I., Zaitseva, I. S., Barabanova, E. A. 2000: Development of Dams in the Russian Federation and NIS Countries. World Commission on Dams. Cape Town.

Marjanac, T., Marjanac, L., Poljak, M., Živčič, M., Bavec, M. 2001: Srpenica seismites - indicators of paleoseismicity in the Upper Soča valley, NW Slovenia. Geologija 44-2. DOI: http://dx.doi.org/ 10.5474/geologija.2001.026

Medmrežje 1: http://earthobservatory.nasa.gov/IOTD/view.php?id=2077 (11.10.2016).

Medmrežje 2: http://earthobservatory.nasa.gov/NaturalHazards/natural_hazards_v2.php3?img_id=14879 (2.7.2008).

Micu, M., Bălteanu, D. 2013: A deep-seated landslide dam in the Siriu Reservoir (Curvature Carpathians, Romania). Landslides 10. DOI: http://dx.doi.org/10.1007/s10346-013-0382-8

Natek, K. 1999: Možnosti nadaljnjega sonaravnega razvoja ob treh sosednjih južnoalpskih rekah: Piavi, Tilmentu in Soči. Dela 13.

National Performance of Dams Program 2008. Stanford University. Medmrežje: http://npdp.stanford.edu/ index.html (1.7.2008). 
Nicoletti, P. G., Parise, M. 2002: Seven landslide dams of old seismic origin in southeastern Sicily (Italy). Geomorphology 46, 3-4. DOI: http://dx.doi.org/10.1016/S0169-555X(02)00074-0

Ocena škode zaradi poplave Drave 5. in 6. 11.2012: Končno poročilo, 18. 9. 2013. Inštitut za vode Republike Slovenije. Ljubljana, 2013. Medmrežje: http://www.izvrs.si/project/ocena-skode-zaradi-poplavedrave-5-in-6-11-2012-koncno-porocilo-18-9-2013/ (11.10.2016).

Panoramio, 2008. Medmrežje: http://www.panoramio.com/photos/original/1272079.jpg (1.7.2008).

Popit, T. 2010: Fosilni plaz pri Selu v Vipavski dolini. Življenje in tehnika 61, 7-8.

Prediction of Embankment Dam Breach Parameters. Dam Safety Office. Medmrežje: http://www.usbr.gov/ pmts/hydraulics_lab/pubs/PAP/PAP-0735_DSO-98-004.pdf (1.7.2008).

Radinja, D., Šifrer, M., Lovrenčak, F., Kolbezen, M., Natek, M. 1976: Geografske značilnosti poplavnega področja ob Pšati. Geografski zbornik 15.

Rangachari, R., Sengupta, N., Iyer, R. R., Banerji, P., Singh, S. 2000: Large Dams: India’s Experience. World Commission on Dams. Cape Town. Medmrežje: www.dams.org (1.7.2008).

Rybář, J., Stemberk, J., Wagner, P. 2002: Landslides. Lisse.

Schuster, R. L. 1979: Reservoir-induced landslides. Bulletin of the International Association of Engineering Geology 20-1. DOI: http://dx.doi.org/10.1007/BF02591233

Schuster, R. L. (ur.) 1986: Landslide Dams: Processes, Risk and Mitigation. New York.

Schuster, R. L., Alford, D. 2004: Usoi landslide dam and Lake Sarez, Pamir Mountains, Tajikistan. Environmental and Engineering Geoscience 10-2. DOI: http://dx.doi.org/10.2113/10.2.151

Semenza, E. 2001: La storia del Vaiont; raccontata dal geologo, che ha scoperto la frana. San Bartolomeo in Bosco.

Semenza, E., Ghirotti, M. 2000: History of the 1963 Vaiont slide: the importance of geological factors. Bulletin of Engineering Geology and the Environment 59-2. DOI: http://dx.doi.org/10.1007/s100640000067

Superchi, L., Floris, M., Ghirotti, M., Genevois, R., Jaboyedoff, M., Stead, D. 2010: Technical note: Implementation of a geodatabase of published and unpublished data on the catastrophic Vaiont landslide. Natural Hazards and Earth System Sciences 10. DOI: http://dx.doi.org/10.5194/nhess-10-865-2010

Šifrer, M. 1965: Kvartarni razvoj doline Soče med Tolminom in Ročinjem. Elaborat. Inštitut za geografijo SAZU. Ljubljana.

Tacconi Stefanelli, C., Catani, F., Casagli, N. 2015: Geomorphological investigations on landslide dams. Geoenvironmental Disasters 2. DOI: http://dx.doi.org/10.1186/s40677-015-0030-9

The 1925 Santa Barbara Earthquake: The Dam Break. Medmrežje: http://projects.crustal.ucsb.edu/sb_eqs/ 1925/sheffield.html (30.6.2008).

The Gateway to astronaut photography. Medmrežje: http://eol.jsc.nasa.gov/scripts/sseop/photo.pl?mission= ISS002\&roll=E\&frame $=7771$ (1.7.2008).

The Vaiont landslide electronic bibliographic batabase. Natural Hazards and Earth System Sciences Supplement File, 2010. Medmrežje: http://www.nat-hazards-earth-syst-sci.net/10/865/2010/ nhess-10-865-2010-supplement.pdf (11.10.2016).

The Vajont rockslide. Italian Journal of Engineering Geology and Environment - Book Series 6: International Conference on Vajont - 1963-2013 - Thoughts and Analyses After 50 Years Since the Catastrophic Landslide. Padua. Medmrežje: http://www.ijege.uniromal.it/rivista/international-conferenceon-vajont-1963-2013-thoughts-and-analyses-after-50-years-since-the-catastrophic-landslide/ topic-6-the-vajont-rockslide/ (11.10.2016).

Toccoa Flood. USGS. Medmrežje: http://ga.water.usgs.gov/news/historical-toccoa/ (11.10.2016).

Trontelj, M. 1997: Kronika izrednih vremenskih dogodkov XX. stoletja. Ljubljana.

Vries, L. 2005: Dam breaks at Missouri Power Plant. CBS News, 14. 12.2005. Medmrežje: http://www.cbsnews.com/news/dam-breaks-at-missouri-power-plant/ (11. 10.2016).

Wahl, T. L. 1998: Prediction of Embankment Dam Breach Parameters: A Literature Review and Needs Assessment. Bureau of Reclamation Dam Safety Office. Medmrežje: https://www.usbr.gov/ssle/ damsafety/TechDev/DSOTechDev/DSO-98-04.pdf (11.10.2016). 
Wolter, A., Stead, D., Ward, B. C., Clague, J. J., Ghirotti, M. 2016: Engineering geomorphological characterisation of the Vajont Slide, Italy, and a new interpretation of the chronology and evolution of the landslide. Landslides 13-5. DOI: http://dx.doi.org/10.4408/10.1007/s10346-015-0668-0

Yochum, S., Goertz, L., Jones, P. 2008: Case study of the Big Bay dam failure: Accuracy and comparison of breach predictions. Journal of Hydraulic Engineering 134-9. DOI: http://dx.doi.org/10.1061/ (ASCE)0733-9429(2008)134:9(1285)

Zorn, M. 2002a: Podori na Dobraču. Geografski vestnik 74-2.

Zorn, M. 2002b: Rockfalls in Slovene Alps. Geografski zbornik 42.

Zorn, M. 2003/2004: Nekateri večji skalni podori v Alpah. Ujma 17-18.

Zorn, M., Komac, B. 2009: Nekateri učinki bojevanja na naravno pokrajino. Geografski vestnik 81-2.

\section{Summary: Natural and man-made dams and related hydro-geomorphic processes}

(translated by Blaž Komac)

Slope processes associated with natural impoundments are a frequent phenomenon (Costa and Schuster 1988; Korup 2002; Korup, McSaveney and Davies 2004; Komac, Natek and Zorn 2008; Evans et al. 2011b; Fan et al. 2012), especially in seismically active areas (Komac 2015). In about $60 \%$ cases the dams overspilling or breach occur within one month after the triggering of landslide or rockfall. Sooner or later breaches of natural dams occur in $86 \%$ of cases (Fan et al. 2012). Landslides and rockfalls in artificial impoundments are associated with the construction of dams and mostly occur during their infilling.

The paper deals with the impact of natural dams on slope processes, and vice versa, the influence of slope processes on the reservoirs and associated flooding. We also treat artificial reservoirs, which are often the cause of slope processes. Specifically, we present the 1963 Vaiont landslide in northern Italy, its causes and consequences.

Landslides are often triggered already during the construction of dams, e.g. changes in water levels at their infilling. We present a few examples from the world. In western United States alone 566 dam breaches were recorded in the period 1990-2008 (National... 2008). Often settlements are endangered by fast and high flood wave. Spilled water causes damage and erosion due to high energy. Some areas therefore become unsuitable for agricultural activity or living. In history, this phenomenon has been exploited for military purposes (Zorn and Komac 2009).

Probably the most famous disaster Europe associate with slope processes which plunged into an artificial lake, is the Vaiont landslide (Barla and Paronuzzi 2013; Genevois and Tecca 2013). There is extensive literature about this event and its consequences (e.g. Supechi et al 2010; The Vaiont ... 2010; The Vajont 2013).

Especially in earthquake-prone areas in narrow river valleys in mountainous areas, landslides and rockfalls sometimes cover the valley floor (Zorn 2002a), and create hundreds of meters high earthquake-induced landslide or rockfall barriers. Within a few days' lakes are usually formed behind them. Dams result in a double threat: emerging lake can flood settlements above but also beneath them, as the dam may breach (Costa and Schuster 1991).

In Slovenia, we have witnessed natural damming of watercourses especially in the Alpine regions. Many of them occurred at the end of the Pleistocene (Komac and Zorn 2007), such as the Kuntri rockfall in the Upper Soča region which resulted in the Late-Quaternary Srpenica Lake (Kuščer et al 1974; Zorn 2002b). We observed a rockfall dam in Tolminka Valley in 2004 (Komac and Zorn 2009). Even large Selo rockslide below the Trnovski gozd plateau probably dammed, but certainly deviated the stream of the Vipava River (Komac and Zorn 2007). West of Kobarid the Molida rockfall occurred at the end of the Pleistocene (Zorn 2002b). According to a historian from the $19^{\text {th }}$ century it diverted the flow of 
the Soča River in $6^{\text {th }}$ century (Czoernig 1876). The Radoljna stream (in 1811) and the Hudinja stream (in 1954) landslide damming are known in eastern Slovenia (Trontelj 1997) and in northern Slovenia a landslide dam occurred in 1990 in Podvolovjek Valley (Komac, Natek and Zorn 2008).

Also some artificial dam breaches and outbursts are known in Slovenia. A small-scale event occurred in the Pšata Valley in 1968 (Radinja et al. 1976), and in the Drava Valley in 1998 when the river flooded 350 houses. In 2012 anthropogenic flooding and dam overspilling occurred in the Drava Valley due to inconsistent operation of Austrian hydroelectric power plants. 